\author{
UNIVERSIDADE DE SÃO PAULO \\ ESCOLA DE ENGENHARIA DE SÃO CARLOS \\ Departamento de Engenharia Mecânica
}

MOACIR APARECIDO ROSSI

Método prático para otimização do ciclo de retificação transversal de precisão

São Carlos

2009 
MOACIR APARECIDO ROSSI

\section{Método prático para otimização do ciclo de retificação transversal de precisão}

Dissertação apresentada ao Departamento de Engenharia Mecânica, como parte dos requisitos para obtenção do título de mestre em Engenharia Mecânica.

Área de Concentração: Manufatura

Orientador: Eraldo Jannone da Silva

São Carlos

2009 
AUTORIZO A REPRODUÇÃO E DIVULGAÇÃO TOTAL OU PARCIAL DESTE TRABALHO, POR QUALQUER MEIO CONVENCIONAL OU ELETRÔNICO, PARA FINS DE ESTUDO E PESQUISA, DESDE QUE CITADA A FONTE. 


\section{FOLHA DE JULGAMENTO}

Candidato: Engenheiro MOACIR APARECIDO ROSSI

Dissertação defendida c julgada em 13/03/2009 perante a Comissão Julgadora:

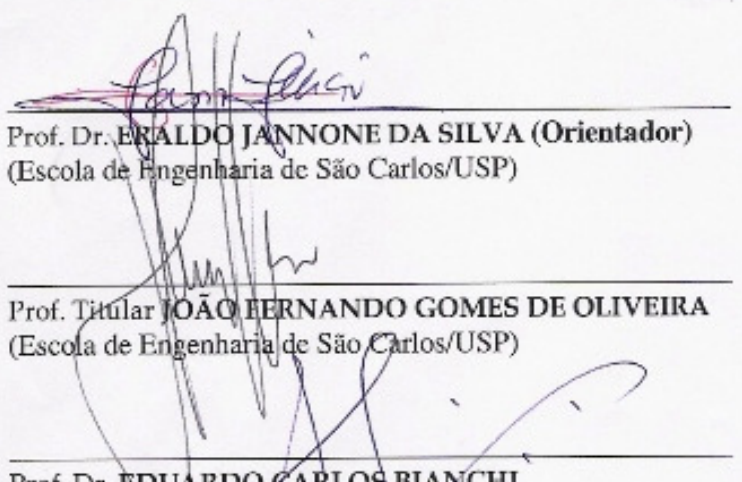

APROVODO

Prof. Dr. ELAALDO JANNONE DA SILVA (Orientador)

(Escola de Angenharia de São Carlos/USP)

Prof. Dr. IDUARDO CARLOS BIANCHI

(Universidade:Estaduał Paylista Julio de Mesquita Filho"/Campus de Bauru )

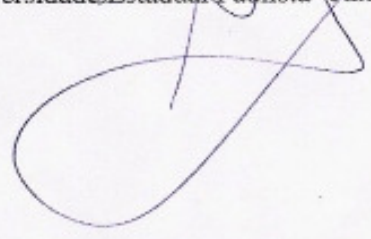

APROVAdO
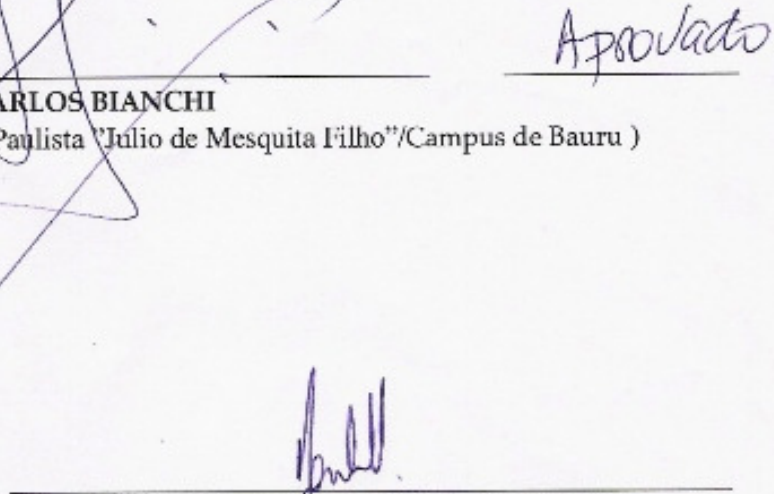

Prof. Associadd JONAS DE CARVALHO

Coordenador do Programa de Pós-Graduação em Engchharia Mecânica

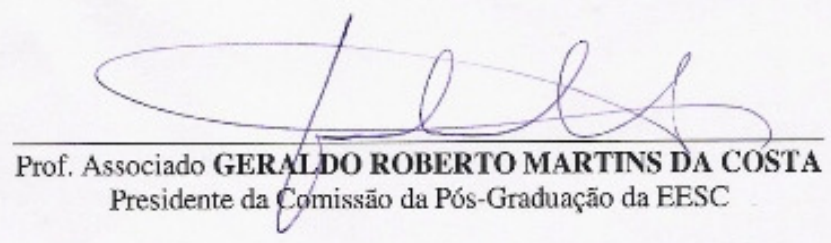


À minha esposa Beth e meu filho André pela presença durante a realização desta dissertação. 


\section{AGRADECIMENTOS}

Sempre, ao ser citado este projeto, serão lembrados com meus profundos agradecimentos:

- Prof Dr. Eraldo Jannone da Silva, meu orientador e amigo, pela pronta dedicação e orientação na condução e conclusão desta dissertação.

- Prof. Titular João Fernando Gomes Oliveira, pelo apoio e por acreditar na realização deste projeto.

- Prof. Titular Eduardo Carlos Bianchi, pelas valiosas sugestões e observações quanto à apresentação deste trabalho.

- Aos técnicos do Laboratório de Otimização de Processos de Fabricação, do NUMA - EESC USP, Adolfo e Ariel, pela disposição em colaborar prontamente. 
"Os homens comuns olham para o que existe e perguntam: Por quê?

Os homens incomuns olham para o que não existe e perguntam: Por que não?"

George Bernard Shaw 


\section{RESUMO}

ROSSI, M. A. Método prático para otimização do ciclo e retificação transversal de precisão. 2009. Dissertação (Mestrado) - Faculdade de Engenharia Mecânica, Universidade de São Paulo, São Carlos, 2008.

Este trabalho descreve uma forma prática para planejamento do ciclo de operação de retificação por mergulho, em função da especificação dimensional da peça e da rigidez da máquina. Essa otimização é estendida além do ciclo, envolve produzir lotes de peças com dispersão das dimensões dentro de limites especificados.O tempo de set up, que normalmente não está incluído no tempo de processo, aqui é incluído e considerado. A primeira atividade de laboratório teve como objetivo confirmar a relação entre a quantidade de material removido em função do tempo de spark-out. A segunda atividade comprovou a existência de uma relação linear entre a velocidade de avanço radial do rebolo e o diâmetro final da peça. A terceira atividade confirmou a existência de uma relação entre a velocidade de avanço radial e o índice de capabilidade especificado para o processo. Ainda, foi sugerida a inclusão deste processo proposto num programa $\mathrm{CNC}$ da máquina, de forma a se obter automaticamente o set-up. Concluiu-se que o método aqui apresentado reduziu significativamente o tempo de setup da máquina conferindo um incremento de produtividade aos processos que fizerem uso deste princípio.

Palavras-Chave: produtividade, retificação cilíndrica transversal, otimização de ciclo, capacidade, capabilidade. 


\begin{abstract}
ROSSI, M. A. Practical way to optimization the cycle of precision plunge grinding. 2009. Dissertation (Master Science) - School of Mechanical Engineering of São Carlos, University of São Paulo, 2009.

This work shows a practical way to design the cycle of a plunge grinding process as a function of workpiece dimensional specification and the machine stiffness. This optimization is extended beyond the cycle, it's included make batch of parts with dispersion within the specification limits. The set-up time, that usually isn't in the process time, here it was included and focused. The first activity of laboratory had an objective to confirm the relation of the amount of material removed as a function of spark out time. The second activity has been confirmed the linear relationship between the infeed velocity of the grinding wheel and the final diameter of the workpiece. The third activity has been confirmed the relation of the infeed velocity and the capability of the process. Yet, it was suggested to include this procedure in a CNC set of the machine to allow a faster and automatic set up. So, this work shows a conclusion that the set up time can be reduced a lot, allowing higher productivity for who use this procedure.
\end{abstract}

Keywords: productivity, cylindrical plunge grinding, cycle optimization, capability. 


\section{LISTA DE ILUSTRAÇÕES}

Figura 1. O ciclo no processo de retificação, mostrando a posição relativa entre o rebolo e a peça num processo de retificação sem centros

Figura 2. Influência do índice $\mu$ na deformação da máquina

Figura 3. Ciclo convencional, genérico, do processo de usinagem.

Figura 4. Ciclo alterado para obtenção de spark-out acelerado.

Figura 5. Dissipação do calor gerado no processo de retificação. .20

Figura 6. Influência do fluído de corte na força normal de corte. .22

Figura 7. Influência da taxa específica de retificação na força normal de corte.

Figura 8. Influência da taxa especifica de retificação na rugosidade.

Figura 9. Comparativo entre o rebolo antes e após a dressagem .24

Figura 10. Variáveis influentes no grau de recobrimento. .25

Figura 11. Influência do grau de recobrimento na força normal de corte. .26

Figura 12. Elementos participantes do processo de dressagem.

Figura 13. Influência da dureza da peça na força normal de corte.

Figura 14. Influência do tempo de faiscamento na força normal de corte. .28

Figura 15. Distribuição normal de uma grandeza qualquer

Figura 16. Definição do Cp e Cpk em função da dispersão

Figura 17. Corpo de prova utilizado nos ensaios

Figura 18. Detalhe mostrando a peça fixada na máquina

Figura 19 Influência do tempo de spark-out (faiscamento) no diâmetro da peça após a usinagem.

Figura 20. Relação entre a velocidade de avanço e a variação de diâmetro da peça, sem sparkout

Figura 21. Relação entre a velocidade de avanço e a variação de diâmetro da peça, com sparkout $10 \mathrm{~s}$ 
Figura 22. Relação entre a velocidade de avanço e a deformação ocorrida no sistema RMP.

Figura 23. Distribuição normal do diâmetro de uma amostra de peças ...................................54

Figura 24. Relação entre os sobremetal em cada sub-fase ...................................................56

Figura 25. Método para calculo das velocidades de avanço com $\mathrm{Cp}=1,25$.......................60

Figura 26. Método para calculo das velocidades de avanço com $\mathrm{Cp}=1,33$.......................61

Figura 27. Método para calculo das velocidades de avanço com $\mathrm{Cp}=2,25$........................61

Figura 28. Diâmetro obtido para cada uma das peças usinadas com Vf3=0,65 mm/s e

$\mathrm{Cp}=2,25$.

Figura 29. Diâmetro obtido para cada uma das peças usinadas com Vf3=1,04 mm/s e $\mathrm{Cp}=1,40$

Figura 30. Diâmetro obtido para cada uma das peças usinadas com Vf3=1,17 mm/s e

$\mathrm{Cp}=1,25$

Figura 31. Relação entre a Cp prevista e Cp real 65

Figura 32. Gráfico mostrando a relação proporcional entre a velocidade de avanço do rebolo (Vf) e a capabilidade do processo (Cp)

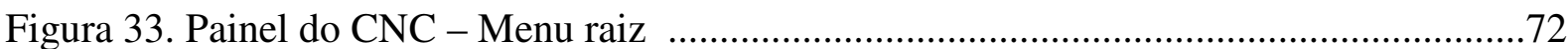

Figura 34. Painel do CNC - Tela para inserção das condições de contorno ............................78

Figura 35. Painel do CNC - Tela mostrando a maquina configurada .73 


\section{LISTA DE TABELAS}

Tabela 1 - Valores da Capacidade do Processo e quantidade de não-conformidades para uma distribuição normal

Tabela 2 - Valores mínimos recomendados para Índice de Capabilidade do Processo (Cpk)

Tabela 3 - Relação entre o tempo de spark-out e a redução no diâmetro $(\Delta \varnothing)$ medida.

Tabela 4 - Dimensões obtidas na usinagem sem spark-out e com spark-out $10 \mathrm{~s}$ .50

Tabela 5 - Parâmetros para realização do Teste de Rigidez .59

Tabela 6 - Resultados após usinagem das três amostras 62

Tabela 7 - Variação do desvio padrão em função da velocidade de avanço .64

Tabela 8 - Comparativo entre a capabilidade prevista e a capabilidade efetiva .64 


\section{LISTA DE SIGLAS}

$\mathrm{Cp} \quad$ Índice de capabilidade

CEP Controle Estatístico do Processo

IQA Instituto da Qualidade Automotiva

RMP Rebolo-Máquina-Peça 


\section{SUMÁRIO}

1. INTRODUÇÃ

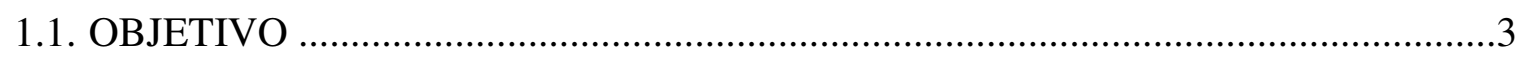

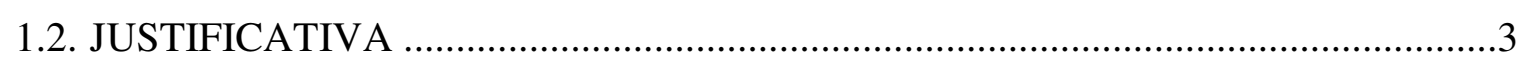

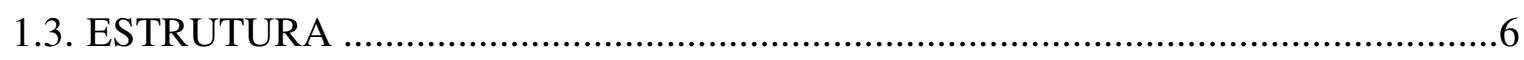

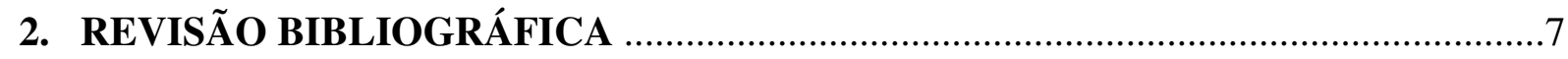

2.1. O CICLO NO PROCESSO DE USINAGEM POR ABRASÃO .................................

2.1.1. APROXIMAÇÃO, AFASTAMENTO E TROCA DA PEÇA............................8

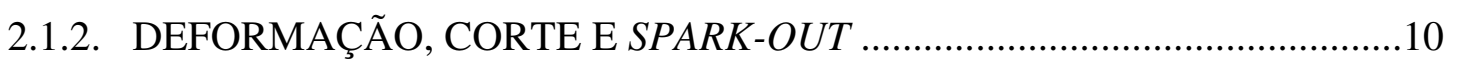

2.1.3. O SET-UP NA RETIFICAÇÃO ................................................................. 10

2.2. MÉTODOS UTILIZADOS PARA DETERMINAÇÃO DO CICLO DE USINAGEM

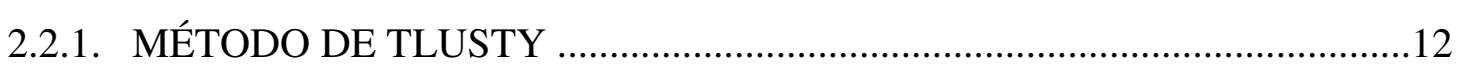

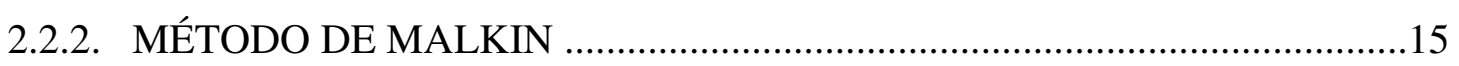

2.2.3. CONSIDERAÇÕES SOBRE OS MÉTODOS APRESENTADOS.................17

2.3. INFLUÊNCIAS NAS DEFORMAÇÕES ELÁSTICAS DO SISTEMA REBOLO-

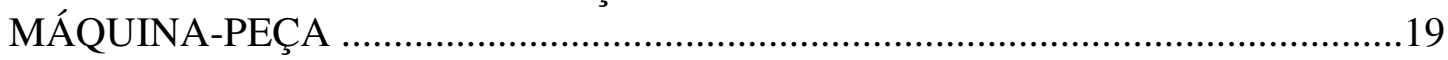

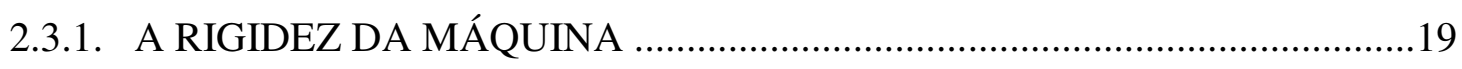

2.3.2. INFLUÊNCIAS NA FORÇA NORMAL DE CORTE ...................................21

2.3.2.1. INFLUÊNCIA DO FLUIDO DE CORTE.............................................21

2.3.2.2. INFLUÊNCIA DO TAXA ESPECÍFICA DE RETIFICAÇÃO..............22

2.3.2.3. INFLUÊNCIA DO DESGASTE RADIAL DO REBOLO DE CORTE ..23

2.3.2.4. INFLUÊNCIA DO MATERIAL DA PEÇA ...........................................27

2.3.2.5. INFLUÊNCIA DO TEMPO DE SPARK-OUT ......................................27

3. CAPABILIDADE APLICADO A PROCESSOS DE USINAGEM..........................29

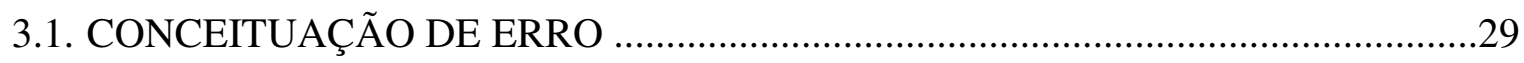

3.1.1. ERROS GEOMÉTRICOS........................................................................

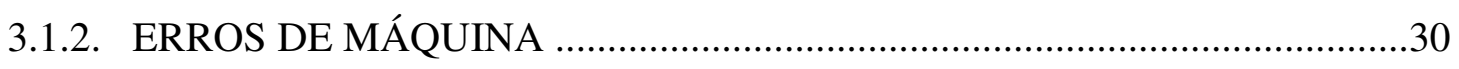

3.2. INFLUÊNCIAS NA CAPABILIDADE EM PROCESSOS DE RETIFICAÇÃO .....33

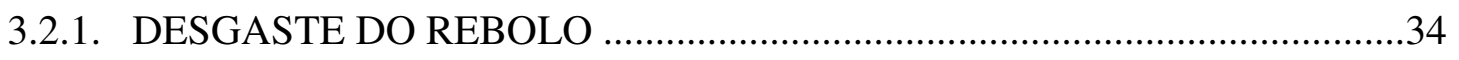

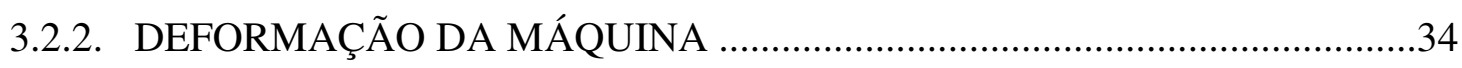

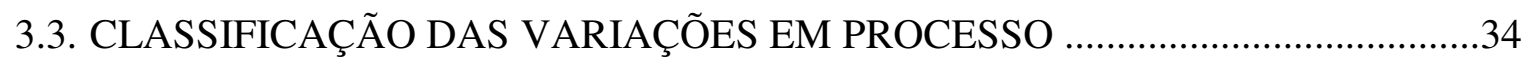

3.3.1. VARIAÇÃO NATURAL, ALEATÓRIA OU RANDÔMICA .........................35

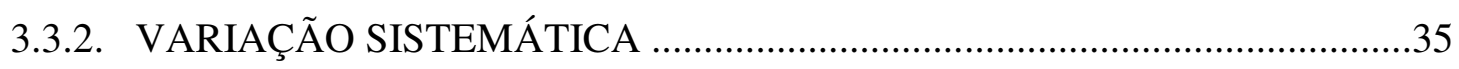

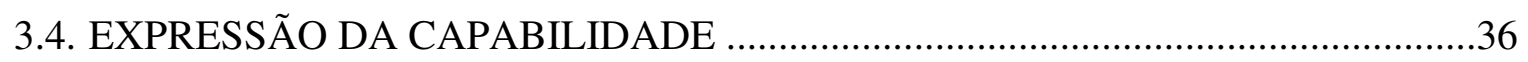


4. METODOLOGIA 42

4.1. FORMULAÇÃO DO PROBLEMA 42

4.2. CARACTERIZAÇÃO DO PROCEDIMENTO E DOS EQUIPAMENTOS UTILIZADOS 43

4.2.1. MÁQUINA-FERRAMENTA / INSTRUMENTOS 43

4.2.2. CORPOS-DE-PROVA 43

4.2.3. CONDIÇÕES DE DRESSAGEM / SISTEMA DE DRESSAGEM .44

4.2.4. FLUÍDO DE CORTE .44

4.2.5. FERRAMENTA DE CORTE 45

4.3. PROCEDIMENTOS PARA VERIFICAÇÃO DA RELAÇÃO ENTRE O TEMPO DE SPARK-OUT E O DIÂMETRO FINAL DA PEÇA .46

4.4. PROCEDIMENTOS PARA VERIFICAÇÃO DA RELAÇÃO ENTRE A VELOCIDADE DE AVANÇO E A DEFORMAÇÃO DA MÁQUINA

4.5. VALIDAÇÃO DA EXISTÊNCIA DE UMA RELAÇÃO ENTRE A VELOCIDADE DE AVANÇO E A CAPABILIDADE (Cp)

5. RESULTADOS - ANÁLISE E DISCUSSÃO .62

6. CONCLUSÕES 67

7. SUGESTÕES PARA TRABALHOS FUTUROS .68 REFERÊNCIAS BIBLIOGRÁFICAS 69 APÊNDICE A - MÉTODO PARA DETERMINAÇÃO AUTOMÁTICA DO TEMPO DE SET-UP. 


\section{INTRODUÇÃ̃o}

O grande diferencial de sucesso num empreendimento está intimamente ligado ao menor tempo de processamento de seu produto, ou seja, maior produtividade.

No final da década de 90, os consumidores abandonaram as marcas tradicionais e passaram a comprar de quem lhes apresentava uma oferta que melhor atendesse suas necessidades, com menor custo e maior facilidade de obtenção (HAMMER, 2000).

A globalização acrescentou a isso novos produtos, nova qualidade, novos preços, enfim aumentou muito o poder do cliente.

Por isso, esforços em pesquisa têm sido concentrados em aumentar a produtividade nos processos de fabricação, ou seja, diminuir a quantidade de recursos em função do tempo necessário para sua realização.

Em relação ao processo de retificação diversos trabalhos foram realizados no sentido de otimizar o tempo de ciclo, como: compreensão e redução de problemas com o número de lobos presentes nas peças (GALLEGO, 2006), eliminação ou redução de facetamentos (LIZARRALDE et al., 2005), eliminação de vibrações (GIMENEZ, 1994), aumento de rigidez da máquina (SIMNOFSKE, 2006), otimização do ciclo com aceleração do tempo de spark-out (MALKIN, 1981), entre outros.

As abordagens feitas ao tema "otimização do ciclo" se restringem ao ciclo de usinagem tão somente. Porém quando se fala em produtividade isto não é suficiente. A produtividade não estará otimizada se o processo não se apresentar estável, com uma dispersão dimensional dentro de uma faixa de valores entendidos como ótimos.

Assim, no processo da retificação transversal, a redução sistemática no ciclo de 
operação da máquina é fator crucial para tornar o processo mais competitivo. No entanto, quando se fala em produtividade a abrangência é maior e o foco deve ir além da minimização do ciclo, deve também incluir uma estabilização do processo. Com isso a produtividade poderá ser alcançada plenamente.

A retificação é um processo que apresenta grande quantidade de variáveis, (CINCINNATI MILACRON, 1996), como:

FLUÍDO DE CORTE: Tipo, concentração, lubricidade, condutividade térmica, pressão / vazão, filtração adequada, forma do bico do aspersor, posição do bico aspersor, estabilidade da concentração, temperatura, reatividade.

MÁQUINA: velocidade da peça, taxa de remoção especifica, rigidez dinâmica, rigidez estática, rotações / movimentos, guias, vibrações induzidas, alinhamentos, desbalanceamentos, acuracidade dos mancais.

REBOLO: rotação, tipo de grão, tamanho dos grãos, granulometria dos grãos, tipo de ligante, porosidade, parâmetros de dressagem.

Diversas propostas de pesquisas têm sido feitas envolvendo esse tema e também é grande a quantidade delas que são de difícil aplicação prática ou às vezes muito onerosas e economicamente inviáveis.

Assim, este trabalho oferece uma oportunidade de incremento na produtividade; contribuindo, dessa forma; para uma maior inserção no mercado, das empresas que dele fizerem uso. 


\subsection{OBJETIVO}

Este trabalho tem por objetivo propor uma nova metodologia para a redução do tempo de ciclo em operações de retificação transversal de precisão em processos de produção, através da redução do tempo de ciclo aliada à garantia da capabilidade do processo. Esta metodologia caracteriza-se por apresentar uma forma prática para planejamento (design) do ciclo de operação e da sua estabilidade, tendo como dados de entrada somente a especificação da peça e a rigidez da máquina.

O procedimento a ser descrito procurará reduzir a necessidade da ação do operador nessa tarefa através da redução do tempo de set-up e com isso obter maior produtividade.

Adicionalmente será verificada a possibilidade da inclusão desta metodologia em um software a ser fornecido pelo fabricante da máquina ferramenta, visando assim automatizar os procedimentos da metodologia proposta. Os dados de entrada deste software serão obtidos no momento que antecede o inicio da produção, dispensado assim qualquer preparação prévia.

\subsection{JUSTIFICATIVA}

Segundo Rowe (1997), na retificação, o tempo de set-up tem sido bastante grande devido ao grande número de variáveis que nele influenciam, como: tipo de rebolo, velocidade de corte, velocidade de avanço, tipo de refrigerante, condições de dressagem, entre outros. Assim reduzir este tempo é definitivamente necessário. 
Por ocasião da compra de uma nova máquina, o tempo de set-up normalmente não está incluído no tempo de processo especificado pelo cliente/usuário da máquina, por isso, o fabricante não o inclui no escopo de fornecimento; ficando o cliente/usuário sujeito a uma frustração por ocasião do start-up, e conseqüentemente no decorrer do processo de produção que se segue, devido à ocultação dessa informação. Dessa forma, a consideração deste tempo é suma importância desde o inicio do processo, iniciado na venda da máquina.

Ainda, na retificação esse tempo é bastante dependente da habilidade do operador (OLIVEIRA, 1988) e existe a necessidade de se reduzir esta dependência, já sendo fato que um processo autônomo sobrepõe-se a um processo manual.

Observando-se repetidas vezes os procedimentos utilizados nos set-up em uma empresa fabricante de retificadoras centerless, pôde-se notar o grande empenho dos técnicos em determinar empiricamente a velocidade de avanço e o tempo de spark-out, sempre tendo em vista atender a especificação da capabilidade da máquina estabelecida pelo cliente. Isso sugere a existência de uma relação direta entre a capabilidade (dispersão dimensional da peça) e a velocidade de avanço no processo de retificação transversal, o que permitiria reduzir substancialmente o tempo de set-up e ainda facilitaria a programação do ciclo da máquina. Isto também vem de encontro à necessidade existente de se reduzir o tempo de máquina parada, no sentido de aumentar a produtividade e conseqüentemente reduzir custos.

Sendo assim, a proposição de um método de planejamento do ciclo de retificação através desta dissertação de mestrado, tem como objetivo aumentar a produtividade no processo de retificação transversal, contribuindo na confrontação com o mercado concorrente, o qual vem colocando o Brasil numa posição de desvantagem no cenário mundial.

Observa-se nos últimos anos um grande avanço da economia oriental. Isto tem pressionado o sistema de produção ocidental impelindo-o a entrar nessa concorrência. $\mathrm{O}$ 
Brasil ficou em desvantagem em relação aos países desenvolvidos e de países de economia emergentes segundo um conceituado indicador econômico internacional: Indicador-Chave do Mercado de Trabalho - $5^{\text {a }}$ Edição (última edição publicada até esta data), anunciado pela Organização Internacional do Trabalho (OIT). A produtividade do trabalhador brasileiro foi reduzida em 2,7\%, em comparação com os EUA que aumentou 57\%. Na indústria, a produtividade brasileira caiu de US\$ 7,1 mil (1980) para US\$ 5,9 mil (2005). O que corresponde a 5\% do nível de produtividade americano; essa proporção era de 19\% em 1980, conforme ILO International Labour Organization (2007).

Há uma necessidade urgente em promover a produtividade em países ditos em fase de desenvolvimento, como o Brasil, a fim de tornar nossa economia mais competitiva. Pesquisas são necessárias, no sentido de aumentar a competitividade do produto brasileiro tanto no mercado nacional como no internacional (BENKO, 1999).

Por fim será proposto um software que poderá ser adicionado ao painel do CNC da máquina, visando converter de forma automática os dados de entrada em parâmetros de ajuste da máquina. Esses dados deverão ser obtidos através de um teste de rigidez, cujo detalhamento será descrito nesta pesquisa.

Dessa forma espera-se contribuir com os usuários deste processo de fabricação tanto quanto com os fabricantes, operadores e preparadores de máquinas, no sentido de tornar este processo mais ágil e mais competitivo, bem como oferecer uma inovação ao produto e disponibilizar um tempo maior ao operador para que se dedique às atividades que mais necessitem de suas habilidades profissionais. 


\subsection{ESTRUTURA DO TRABALHO}

No capítulo 2 foi feita uma revisão bibliográfica onde se enquadra o assunto abordado. Nesse capítulo também foram esplanadas as características das etapas que compõem o ciclo do processo de retificação, bem como alguns métodos aplicados na otimização do ciclo definido por alguns pesquisadores de renome. Uma consideração sobre esses métodos também foi apresentada. A raiz desta pesquisa encontra-se embasada na rigidez das máquinas. Ainda neste capítulo descrevem-se também alguns aspectos sobre esse assunto, necessários para o embasamento do que será descrito ao longo do texto. Finaliza-se o capítulo com a descrição de fatores que influenciam na deformação do sistema rebolo-máquina-peça (RMP).

Os conceitos básicos sobre capabilidade de uma máquina são apresentados no capítulo 3, no sentido de conduzir o leitor ao entendimento e elucidação da hipótese apresentada, bem como das conclusões a serem obtidas neste trabalho.

No capítulo 4 é descrita a metodologia empregada para a confirmação da existência de uma relação entre o spark-out e o diâmetro da peça usinada. A seguir é feita a descrição de uma metodologia para confirmar a existência de uma relação entre a velocidade de avanço radial do rebolo e a deformação da máquina, a qual já foi objeto de estudo de diversos pesquisadores como Hahn, Tlusty, Lindsay, Malkin e Lichun (OLIVEIRA, 1988). Por fim, será verificada a existência de uma proporcionalidade entre a velocidade de avanço radial do rebolo e a capabilidade da máquina.

Os resultados obtidos destas investigações serão apresentados no capítulo 5 Resultados - Análise e Discussão. As conclusões obtidas e as sugestões para trabalhos futuros serão apresentadas na sequência - capítulo 6 e 7 respectivamente. 


\section{REVISÃO BIBLIOGRÁFICA}

\subsection{O CICLO NO PROCESSO DE USINAGEM POR ABRASÃO}

O ciclo nos processos de retificação cilíndrica inicia-se com a fixação da peça na máquina e termina quando é retirada.

Pode-se dividir o ciclo de retificação nas seguintes etapas: aproximação, corte, spark-out e afastamento, (MALKIN, 1981), conforme Figura 1.

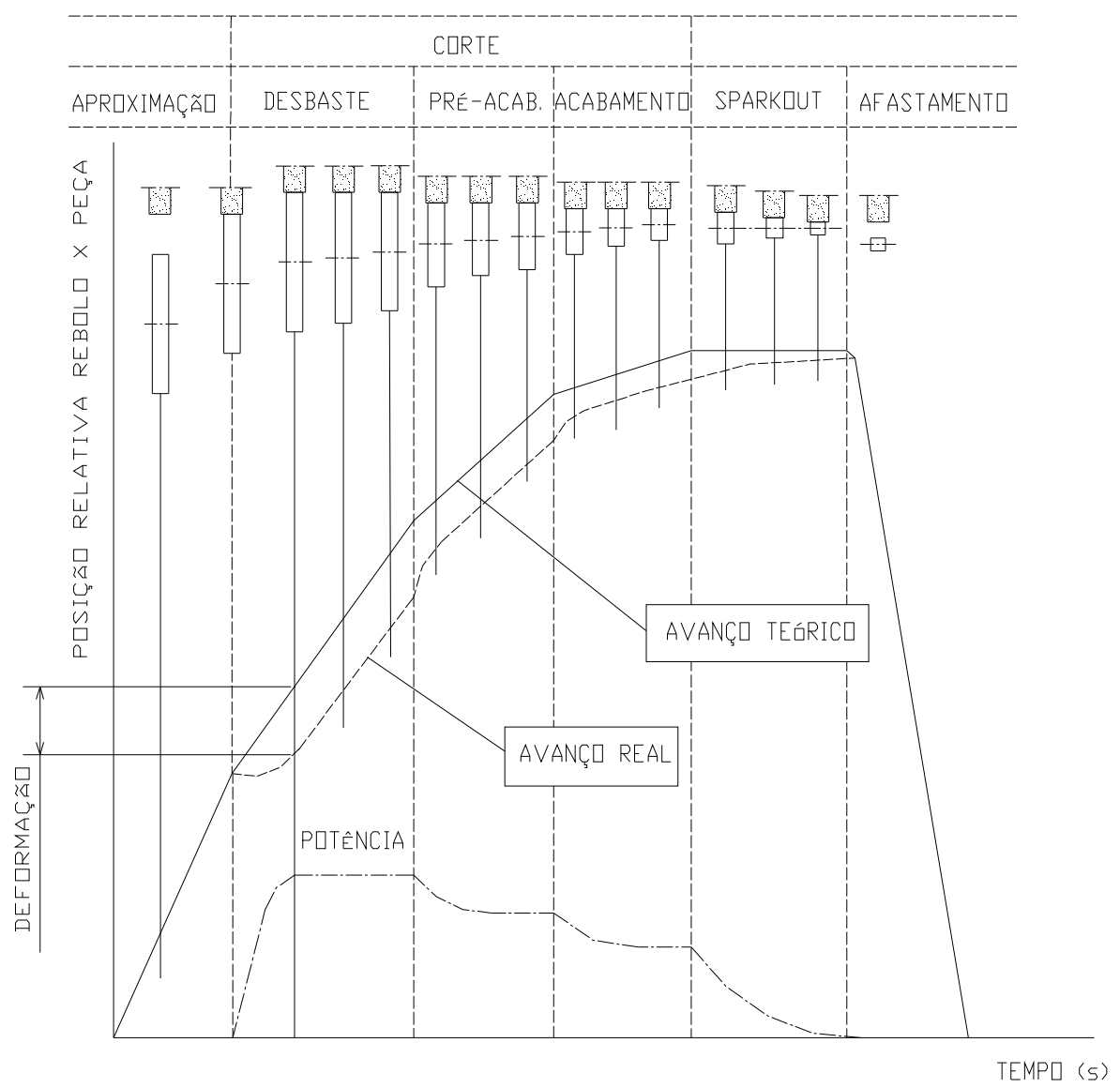

Figura 1. Ciclo no processo de retificação, apresentando a posição relativa entre o rebolo e a peça num processo de retificação sem centros. 
A fase de corte ainda pode ser subdividida em três subfases a fim de se minimizar tempo de ciclo da máquina: desbaste, pré-acabamento e acabamento. A subfase de desbaste é feita com uma velocidade de avanço maior, o que reduz o tempo, no entanto apresenta rugosidade mais alta. Na subfase pré-acabamento a velocidade de avanço é menor, com isso se obtém uma rugosidade mais próxima daquela especificada. Na subfase de acabamento a velocidade de avanço será ajustada para conferir a dimensão e a rugosidade final na peça. A rugosidade poderá ainda ser melhorada com o aumento do tempo de sparkout.

Assim ficam estabelecidas sete etapas que compõem o ciclo total de retificação: aproximação, desbaste, pré-acabamento, acabamento, spark-out (ou centelhamento), afastamento e troca da peça.

A seguir serão detalhadas essas fases e considerações serão feitas sobre as ações já implementadas por pesquisadores no sentido de reduzir o tempo de cada uma delas. Ainda serão abordadas as limitações encontradas.

\subsubsection{APROXIMAÇÃO, AFASTAMENTO E TROCA DA PEÇA}

A aproximação inicia-se com o movimento do rebolo ou da peça no sentido de se aproximarem. $\mathrm{O}$ afastamento ocorre depois da fase da usinagem quando o rebolo e a peça se afastam e por fim procede-se à troca da peça, fechando o ciclo. Nestas fases não há corte, trata-se de tempos improdutivos.

A redução desses tempos pode ser obtida através de mecanismos específicos que racionalizem essas atividades. Cita-se como exemplo o sistema proposto por Malkin (1985) e sistema por emissão acústica proposto por Medalha (2001). O tempo de afastamento 
do rebolo é pequeno se comparado com o tempo total do ciclo de produção em série, de modo que pode ser reduzido com muita facilidade (OLIVEIRA, 1988).

A posição inicial da aproximação é definida em função do sobremetal considerado. Este movimento se dá até a posição de máximo sobremetal e é feito com avanço rápido, em comparação aos avanços na fase de usinagem.

Nota-se que, se o sobremetal tiver grande dispersão dimensional, o posicionamento do rebolo se fará considerando o sobremetal máximo. Isso implica que quando o sobremetal estiver no seu valor mínimo o rebolo se deslocará com avanço de usinagem (avanço mais lento), sem que esta realmente ocorra (OLIVEIRA, 1988).

Por fim, uma menor dispersão dimensional do sobremetal nos levará a um menor tempo de ciclo.

Nos ciclos curtos, até $15 \mathrm{~s}$, os tempos improdutivos influem significativamente no tempo total. Pode-se obter economia de $10 \%$ a $20 \%$ se for utilizado meios de inserção rápida da peça, ou ainda, fazendo a dressagem simultaneamente com a troca da peça (OLIVEIRA, 1988).

Pode-se, ainda, reduzir o tempo de aproximação adotando-se uma taxa de avanço rápida, de forma que esta leve o rebolo até a dimensão de sobremetal máximo. Após isso, com taxa de avanço intermediaria, o rebolo se desloca até encostar-se à peça na posição de sobremetal mínimo (OLIVEIRA, 1988).

Observa-se que as condições de otimização do ciclo descritas são aplicadas à parcela do ciclo onde não ocorre usinagem, isto é, o rebolo não está em contato com a peça. Ressalta-se que estes tempos são improdutivos, portanto não estão relacionados com as condições de usinagem. 


\subsubsection{DEFORMAÇÃO DO SISTEMA RMP, CORTE E SPARK-OUT}

A deformação do sistema RMP inicia-se quando ocorre o contato peça e rebolo; a partir deste ponto reduz-se o avanço a um valor compatível com a velocidade de corte do material da peça e das características do rebolo, principalmente.

Ressaltando que, quando a peça toca o rebolo inicia-se a deformação do sistema RMP, sem que ainda tenha iniciado o corte. Nessa fase ocorre atrito com riscamento da peça. A força normal existente entre a peça e o rebolo vai sendo incrementada até que a fase do riscamento tenha se comutado para a fase do corte (NAKAYAMA, 1980).

O spark-out é a fase onde não mais ocorre o avanço do rebolo sobre a peça. É onde ocorre a retomada da deformação ocorrida durante a fase de corte e é quando se confere circularidade e acabamento na peça.

Nessas etapas é onde ocorre usinagem e também ocorrem os tempos produtivos do ciclo do processo.

\subsubsection{O SET-UP NA RETIFICAÇÃO}

Define-se aqui set-up como sendo o tempo necessário para ajustar o avanço em cada subfase, a velocidade de corte do rebolo de corte (e do rebolo de arraste no caso de retificação sem centros), sobremetal e tempo de spark-out.

O tempo de set-up não está incluído no tempo de ciclo, no entanto tem influencia no ciclo quando se considera a produtividade do processo de um modo geral.

O tempo de set-up costuma ser grande devido ao grande número de variáveis 
que nele influenciam, como: tipo de rebolo, velocidade de corte, velocidade da peça, tipo de refrigerante e condições de dressagem e condições de usinagem.

Um grande tempo de set-up pode até mesmo inviabilizar um processo, uma vez que se refere a um tempo sem produção e tem um custo a ele associado.

O processo de set-up normalmente ocorre da seguinte forma: uma vez definidas as variáveis acima; passa-se, então, a usinar algumas peças para avaliação quanto ao atendimento do especificado. Em cada uma delas é verificado se o diâmetro está dentro da tolerância especificada, se existem erros de forma e se seu acabamento superficial atende o especificado. Ajustes vão sendo feitos conforme requerido até que a especificação tenha sido atendida. Isso feito passa-se a avaliar o processo quanto à sua uniformidade, consistência e capabilidade.

Todo esse processo faz parte de um set-up dito convencional. Essa atividade pode requerer horas ou até mesmo dias para se chegar a uma condição satisfatória.

Aqui fica claro que o set-up no processo de retificação ainda é, de fato, dependente da habilidade do operador da máquina (OLIVEIRA, 1998). Este estudo permitirá também que se otimize o set-up, reduzindo a dependência de habilidades humanas, vindo de encontro ao objetivo de se obter maior produtividade.

\subsection{MÉTODOS UTILIZADOS PARA DETERMINAÇÃO DO CICLO DE USINAGEM}

Descreve-se a seguir, de uma forma resumida, as propostas de dois renomados autores para redução do ciclo de usinagem em processos de retificação. 


\subsubsection{MÉTODO DE TLUSTY}

Tlusty (1970) definiu o coeficiente $R$ como sendo a relação entre a força normal de corte $\left(F_{n}\right)$ e a profundidade de penetração do rebolo na peça (a):

$$
\mathrm{R}=\mathrm{F}_{\mathrm{n}} / \mathrm{a}
$$

Para manter uma profundidade de penetração constante (a) durante a usinagem é necessário que o rebolo mantenha um avanço constante sobre a peça, o que é conferido pela Velocidade de Avanço ( $\left.\mathrm{V}_{\mathrm{f}}\right)$, assim:

$$
\mathrm{a}=\mathrm{V}_{\mathrm{f}} \cdot \mathrm{t} \quad \text { onde } \mathrm{t}=\text { tempo }
$$

Substituindo (2) em (1):

$$
\mathrm{R}=\mathrm{F}_{\mathrm{n}} /\left(\mathrm{V}_{\mathrm{f}} \cdot \mathrm{t}\right)
$$

Tlusty (1970) também definiu o parâmetro adimensional $\mu$ que relaciona o nível de influência da força normal de corte na deformação da máquina, para um dado conjunto (RMP):

$$
\mu=\mathrm{R} / \mathrm{K}_{\mathrm{r}} \quad \text {; onde } \mathrm{K}_{\mathrm{r}} \text { é a rigidez radial do sistema RMP }
$$

Introduzindo (3) em (4):

$$
\mu=F_{n} /\left(V_{f} \cdot t \cdot K_{r}\right)
$$

Isolando Fn, obtém-se a expressão para a força normal:

$$
\mathrm{F}_{\mathrm{n}}=\mu \cdot \mathrm{K}_{\mathrm{r}} \cdot \mathrm{V}_{\mathrm{f} \cdot \mathrm{t}}
$$

Da expressão (6) destaca-se que $F_{n}=f\left(V_{f}\right)$, para uma determinada máquina. Esta expressão será objeto de estudo no item 4.4 desta dissertação.

O índice $\mu$ é definido em função das características do processo: velocidade de 
corte, velocidade da peça, características do rebolo e também das condições de dressagem. $\mathrm{O}$ índice $\mu$ representa a deformação do sistema RMP, isto é, é a diferença entre a posição real e a posição desejada da peça em relação ao rebolo de corte, indicada por Z/S e X/S na Figura 2:

$\mathrm{Z}=$ posição em que o rebolo estaria se não houvesse deformações.

$\mathrm{S}=$ penetração do rebolo por volta da peça obra.

$\mathrm{X}=$ posição do rebolo

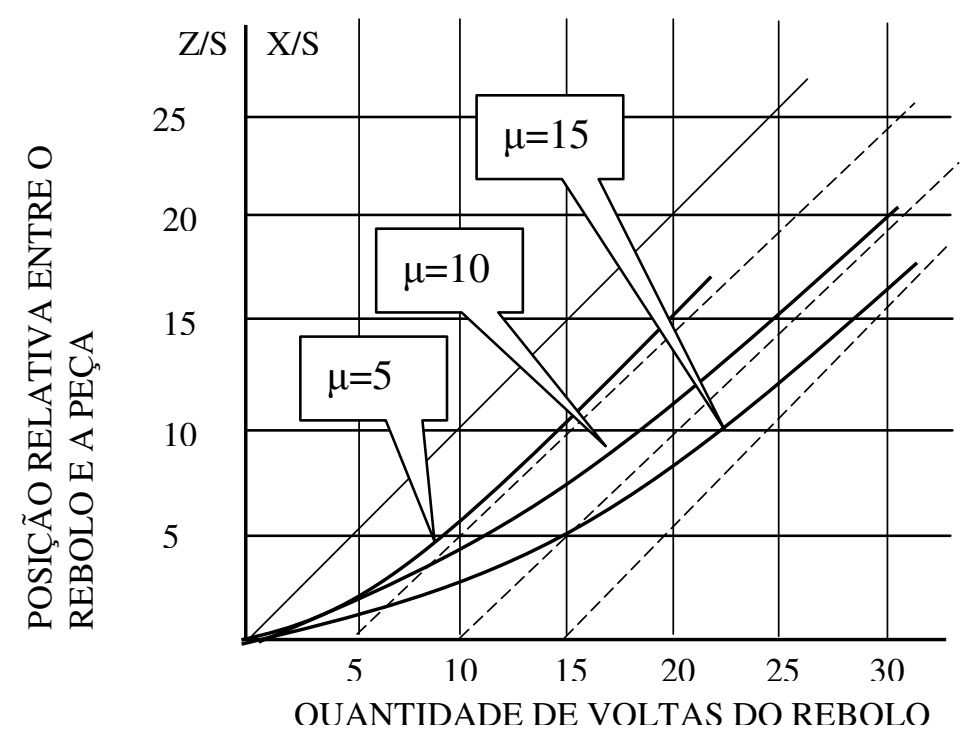

Figura 2. Influência do índice $\mu$ na deformação da máquina. (TLUSTY, 1970)

Assim, um alto valor de $\mu$ representa um sistema pouco rígido onde o aumento da força normal de corte com a profundidade de corte é grande, e vice-versa, conforme pode ser observado na Figura 2.

Uma forma de se reduzir o ciclo de usinagem é com a minimização da relação $\mu$ (TLUSTY, 1970). Para isso pode-se:

a) Aumentar $K_{r}$ selecionando-se um sistema RMP que apresente maior 
rigidez. Influi, ainda, na rigidez da máquina: diâmetro do rebolo, diâmetro da peça, material da peça e se a retificação é interna ou externa.

b) Minimizar o índice $\mathrm{R}=\mathrm{F}_{\mathrm{n}} / \mathrm{a}$, de modo a apresentar uma baixa força normal de corte $\left(F_{n}\right)$ por unidade de avanço. Para isso podem-se otimizar os seguintes parâmetros:

b.1) Aumentar a velocidade de corte $\left(\mathrm{V}_{\mathrm{s}}\right)$, a fim de reduzir a força normal de corte, usando-se um rebolo com ligas apropriadas e disponibilizar uma máquina com sistema de fixação (mancais) apropriados para altas rotações, adicionar reforços estruturais e ainda otimizar o sistema de refrigeração.

b.2) Diminuir o diâmetro equivalente (De), de forma a reduzir a área de contato rebolo/peça, e com isso reduzir a força normal de corte. $\mathrm{O}$ diâmetro equivalente, segundo Tlusty (1970), é definido como:

$$
\begin{aligned}
& \text { De }=\text { Dr } /[1 \pm(\operatorname{Dr} / \mathrm{Dp})] \quad \text { onde: } \\
& \qquad \begin{array}{l}
\text { Dr }=\text { diâmetro do rebolo } \\
\text { Dp }=\text { diâmetro da peça } \\
\pm=+ \text { para retificação externa e - para retificação interna } \\
\text { b.3) Selecionar um rebolo com estrutura mais aberta, menos }
\end{array}
\end{aligned}
$$
dura e grãos menores, com isso também é reduzida a força normal de corte.

b.4) Otimizar as condições de dressagem de modo a se obter uma superfície de corte mais agressiva e, mais uma vez, reduzindo a força normal de corte.

Ainda dentro das etapas produtivas podem-se utilizar os chamados sistemas transientes, os quais são descritos no item a seguir. 


\subsection{2 - MÉTODO DE MALKIN PARA OS SISTEMAS TRANSIENTES}

Malkin (1981) propôs um sistema com o objetivo de reduzir o tempo de sparkout e aumentar a velocidade de avanço a fim de reduzir o ciclo de usinagem. Para reduzir o tempo ele propôs duas ações, a primeira consistia em maximizar a velocidade de avanço durante o desbaste e a segunda alterar a forma da curva de desbaste.

A velocidade de avanço máxima foi obtida tendo em vista duas limitações: uma é determinada pela velocidade na qual inicia a queima da peça e a segunda refere-se ao acabamento obtido na peça.

Malkin (1981) observou que o processo de usinagem convencional, na retificação por mergulho, transcorre como mostrado na Figura 3, isto é, à medida que o rebolo avança sobre a peça (ou vice versa na retificação sem centros) a superfície da peça vai se reduzindo de forma espiral. Se o movimento de avanço for reduzido bruscamente de modo a não permitir que a peça complete uma revolução, a sua circularidade fica comprometida. A fim de se obter uma superfície de forma realmente circular, a redução na velocidade de avanço radial deve ser reduzida progressivamente, de modo a permitir que a peça complete no mínimo uma volta antes do final do ciclo.

Um processo convencional básico de retificação consiste em dois estágios: o primeiro avança-se o rebolo sobre a peça com velocidade controlada e constante e o segundo estágio onde a velocidade de avanço é nula e a usinagem continua por certo tempo. Por fim o rebolo recua completando o ciclo.

A curva teórica desse processo diferencia-se da curva real devido à deformação elástica do sistema, como pode ser observado na Figura 3. O desgaste do rebolo também influencia esta diferença, mas não foi considerado para este estudo. 


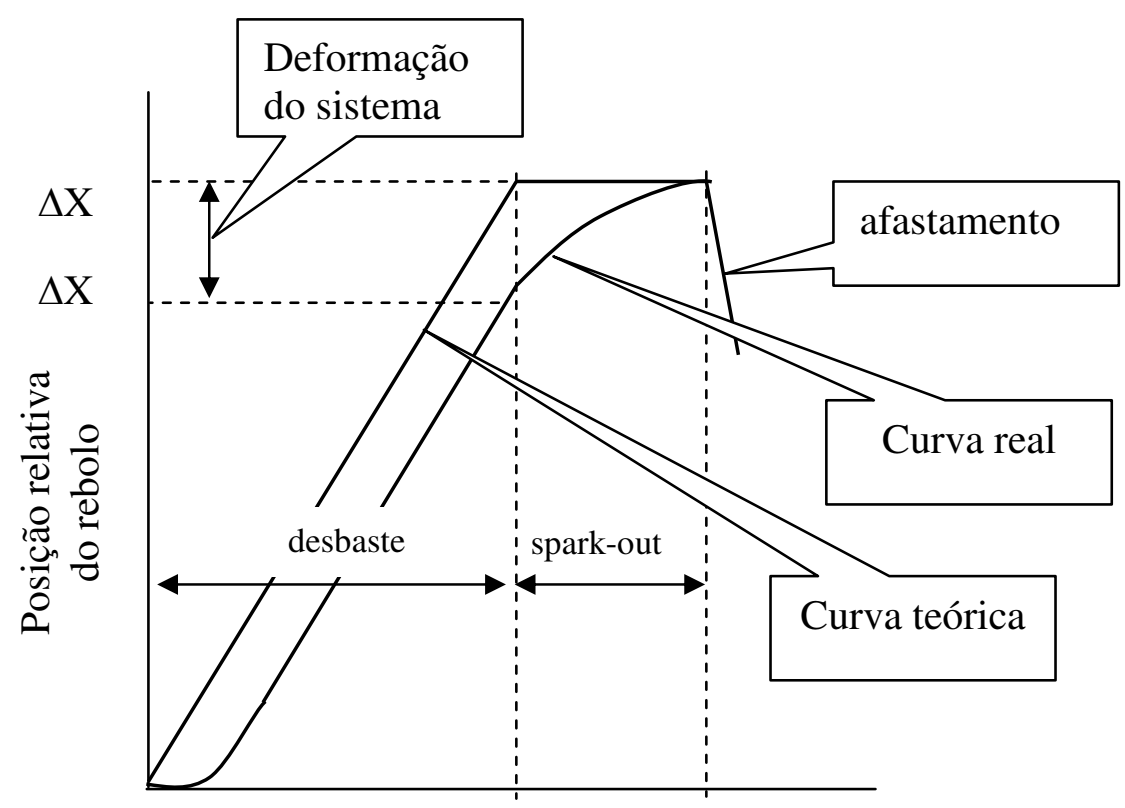

Figura 3. Ciclo convencional, genérico, do processo de usinagem. (MALKIN, 1981).

A diminuição repentina do avanço se reflete num certo retardo no posicionamento entre peça e rebolo. Isso porque o posicionamento real não corresponde àquele definido pela velocidade de avanço regulada, isto devido à deformação elástica do sistema RMP causada pela força normal de corte.

Depois de cessado o avanço ainda é necessário algum tempo para o sistema RMP retomar sua forma original e, à medida que isso ocorre, há uma diminuição progressiva da força normal de corte. Essa fase é denominada spark-out ou centelhamento, é onde a peça toma forma no sentido de se aproximar do círculo perfeito. É nesta fase que se define a rugosidade da peça.

Na segunda ação Malkin propôs um método para acelerar o spark-out, que consistia em avançar o rebolo além de sua posição final, recuando-o em seguida à sua posição final quando, então, a peça já estiver com sua dimensão definida. Com isso a defasagem devido à deformação elástica é eliminada de uma forma mais rápida. Assim concluiu por um 
ciclo com um tempo de spark-out reduzido, isto é, o suficiente somente para conferir acabamento, circularidade e dimensões desejadas, conforme mostrado na Figura 4.

O rebolo avançando além de sua posição final não implica que a peça tenha chegado à sua dimensão final, isto porque houve deformação do sistema RMP. Nesse caso deve ser providenciada uma medição em processo.

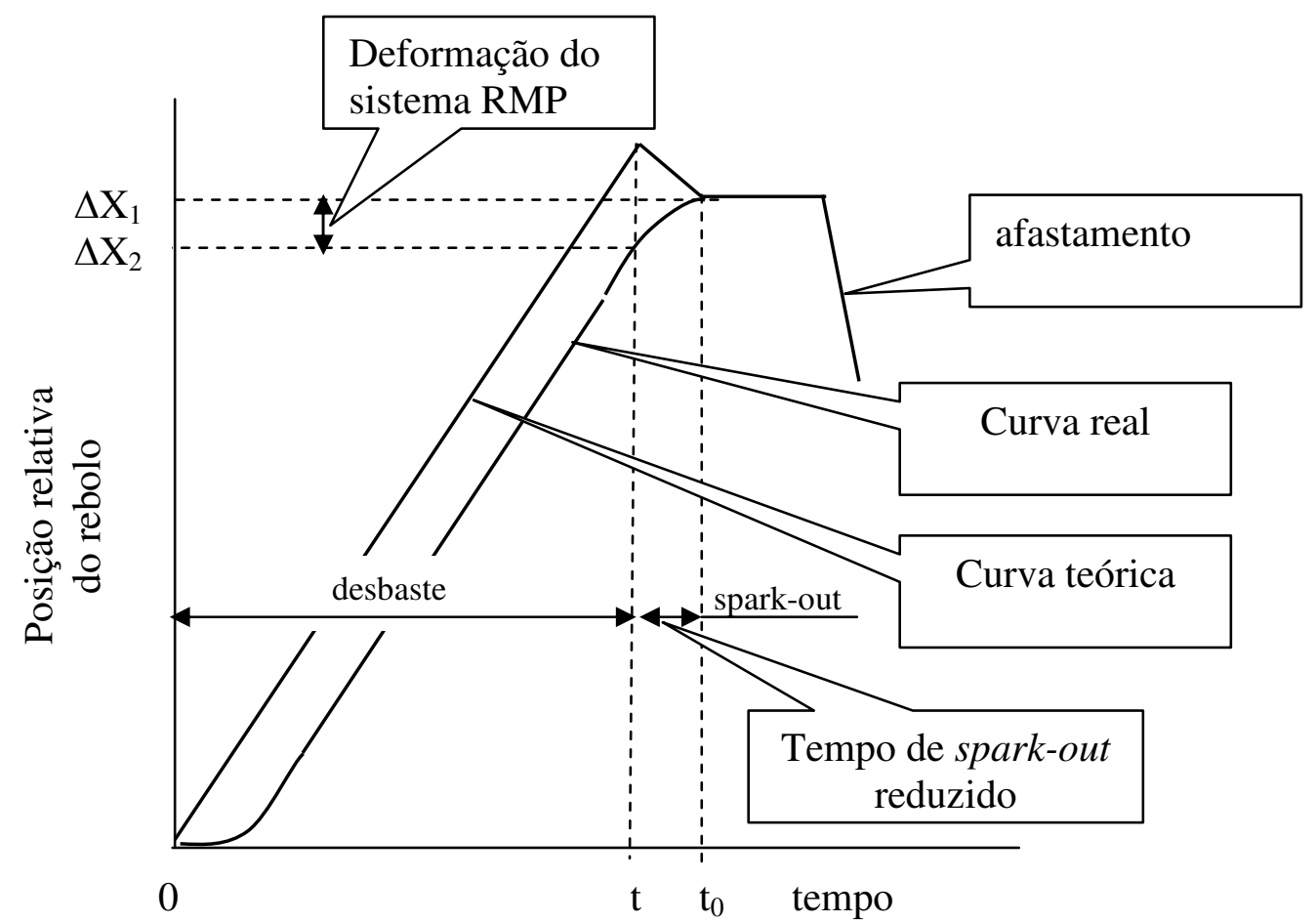

Figura 4. Ciclo alterado para obtenção de spark-out acelerado. (MALKIN, 1981)

\subsubsection{CONSIDERAÇÕES SOBRE OS MÉTODOS APRESENTADOS}

Nota-se que os procedimentos descritos no item 2.2 são utilizados no planejamento do processo de retificação. Essas condições são ajustadas no set-up. Também é notório que as otimizações dos tempos improdutivos não se relacionam com o processo de usinagem propriamente dito. 
Para minimização do fator $\mu$, pode-se adotar a maior velocidade de corte possível e isto está limitado às características físicas da máquina. Uma vez definida a máquina fica estabelecido o primeiro limite para essa velocidade. As características do rebolo também apresentam uma limitação à magnitude da velocidade de corte. O diâmetro equivalente fica definido quando já se tem a imposição do diâmetro da peça feita na especificação de projeto, o diâmetro do rebolo é limitado pela capacidade da máquina em oferecer condições físicas para sua instalação e também pela disponibilidade dos fabricantes. Quanto à dressagem, uma vez especificados as condições apropriadas para o caso, torna-se um parâmetro fixo. A aplicação do sistema descrito por Malkin, reduz o tempo do spark-out e com isso reduz o ciclo total do processo.

Por fim, aplicando-se todos os procedimentos aqui descritos, tanto por Tlusty como por Malkin, obtém-se um tempo mínimo para o processo.

Porém, com isso tudo, a otimização do processo ainda não está concluída: a dimensão final da peça apresentará uma dispersão. A otimização do ciclo não estará completa se esta dispersão não atender às condições econômicas do processo. Essa dispersão pode ser medida por meios estatísticos.

Entende-se assim, que a otimização do processo não termina com a obtenção do tempo mínimo do ciclo, do nível de rugosidade requerido e da circularidade especificada. O processo não estará completamente otimizado somente com essas condições. Faz-se necessário estender o conceito de otimização para a produção em massa, onde as condições econômicas também devem ser ajustadas, e isto não se restringe a reduzir somente o tempo do ciclo.

Assim faz-se necessário voltar a atenção para lotes de produção, fazendo com que sejam produzidos de maneira uniforme e dentro das especificações ao longo do tempo. 
Um processo efetivamente otimizado, além de produzir peças com dimensões, acabamento e geometria especificados, deve ainda:

- Requerer menor custo com mão de obra;

- Reduzir custo com máquinas funcionando sem produzir.

Todos esses itens, quando atendidos convergem para uma característica única: maior produtividade, efetivamente.

Um processo com alta produtividade será aquele que apresentar uma uniformidade e estabilidade ao longo do tempo, isto conduzirá o processo a atender os itens acima citados. Uma vez estável irá requerer menor interferência humana, o tempo produtivo da máquina será maior e o consumo de energia estará direcionado exclusivamente à produção efetiva.

Por fim, os conceitos de otimização apresentados pelos autores citados devem ser estendidos de modo a satisfazer o conceito global de produtividade.

Nesta pesquisa vamos propor uma forma de atingir a estabilidade do processo de uma forma prática e com isso obter uma alta produtividade. Ajustes poderão ser necessários para que se refinem os objetivos.

\subsection{INFLUÊNCIAS NAS DEFORMAÇÕES ELÁSTICAS DO SISTEMA REBOLO- MÁQUINA-PEÇA (RMP)}

\subsubsection{A RIGIDEZ DA MÁQUINA}

À medida que o rebolo avança sobre a peça, com uma determinada velocidade de avanço, origina-se a força normal e tangencial de corte sobre o mesmo. A força normal de 
corte é de alta magnitude, enquanto que a força tangencial é bem menor e age no sentido de cisalhar o cavaco. A força normal de corte causa deformação na máquina. Quanto maior a rigidez da máquina menor será essa deformação. Assim, conhecer estas forças é de fundamental importância para a condução desta pesquisa, o que passamos a detalhar.

A força tangencial de corte, que é utilizada no projeto dinâmico da máquina, é função da energia existente no rebolo de corte (CINCINNATI, 1996):

$$
\begin{aligned}
\mathrm{F}_{\mathrm{t}}=2 \times & 71620 \mathrm{~N} /(\mathrm{n} . \mathrm{d}) ; \quad \text { onde: } \\
\mathrm{F}_{\mathrm{t}} & =\text { força tangencial }(\mathrm{kgf}) \\
\mathrm{N} & =\text { potência existente no rebolo de corte }(\mathrm{HP}) \\
\mathrm{n} & =\text { rpm do rebolo de corte } \\
\mathrm{d} & =\text { diâmetro do rebolo de corte }(\mathrm{cm})
\end{aligned}
$$

A força normal é muito difícil de ser medida. Uma forma prática, para fins comparativos, é estimar essa força através da medida da deformação da máquina para um determinado tipo de rebolo e um determinado material da peça. Tanto maior será a força normal quanto maior for a deformação na máquina (CINCINNATI, 1996).

A intensidade da força radial ou normal de corte é influenciada por:
a) Combinação tipo de rebolo e material da peça,
b) Rotação e diâmetro da peça,
c) Diâmetro e rotação do rebolo
d) Espessura equivalente de corte

O aumento da velocidade de avanço ou de penetração de trabalho conduz a um aumento das forças de usinagem, se forem mantidas as demais variáveis constantes (KONIG, 1980). 


\subsubsection{INFLUÊNCIAS NA FORÇA NORMAL DE CORTE}

É descrito a seguir os principais fatores que influem na força normal de corte:

\subsubsection{Influência do fluido de corte}

O fluído de corte tem como função remover o calor gerado e remover os cavacos na região de corte. O poder lubrificante do fluído reduz a temperatura e a força normal de corte pois reduz a parcela referente ao atrito e reduz o desgaste dos grãos, assim reduz-se a necessidade de manutenção da afiação.

$\mathrm{Na}$ retificação a maior parte do calor é gerada por atrito e riscamento. Outros meios de dissipação são apresentados na Figura 5. O efeito da lubrificação se for utilizado óleo integral produz uma maior redução na temperatura do que se for utilizado uma emulsão (KONIG, 1980). Dessa forma, para a mesma taxa de retificação específica, a força normal específica é menor quando se usa o óleo ao invés da emulsão (KONIG, 1980), como pode ser observado na Figura 6.

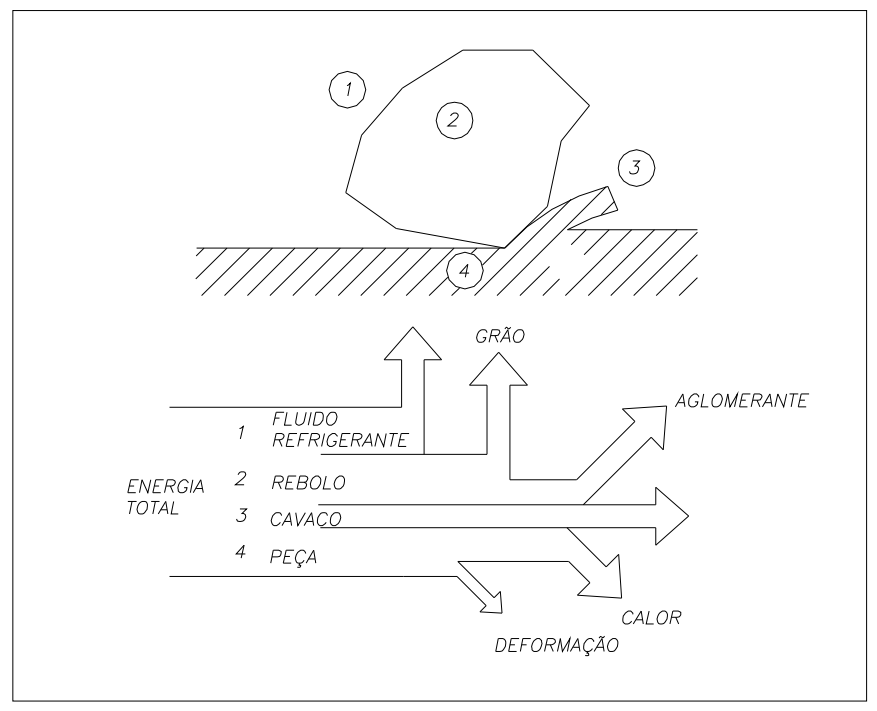

Figura 5. Dissipação do calor gerado no processo de retificação. Adaptado de Dubbel Handbook (1994) 


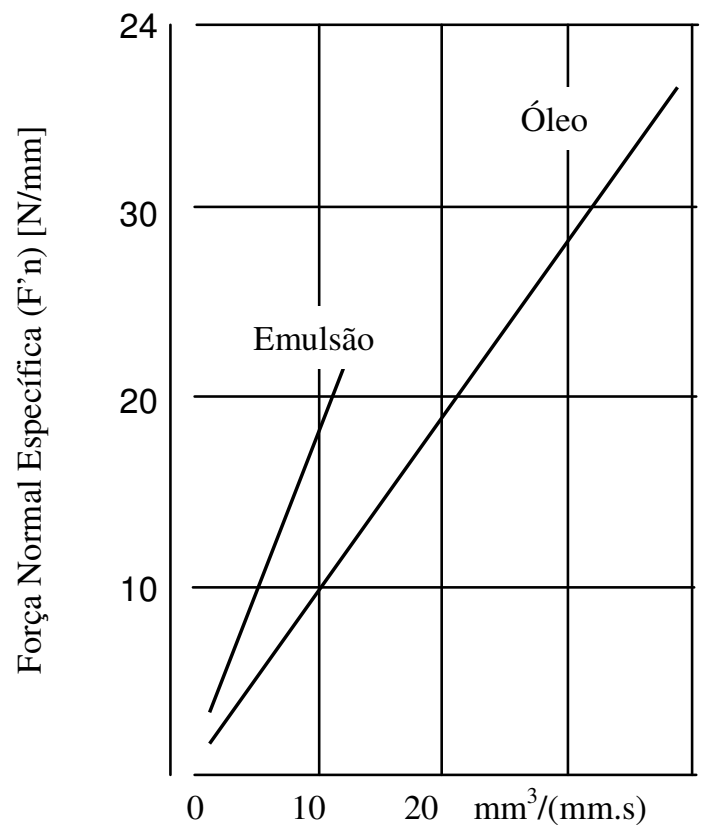

Taxa específica de remoção de material (Q' $\left.{ }_{w}\right)$

Figura 6. Influência do fluído de corte na força normal de corte. Adaptado de Konig (1980)

2.3.2.2 Influência da taxa específica de retificação ( $\left.Q^{\prime}{ }_{w}\right)$

$$
\mathrm{Q}^{\prime}{ }_{\mathrm{w}}=\pi \cdot \mathrm{D}_{\mathrm{w}} \cdot \mathrm{V}_{\mathrm{f}} \quad \text { (para retificação cilíndrica) }
$$

A taxa específica de retificação tem relação com a velocidade de avanço e velocidade tangencial do rebolo, área de contato entre a peça e o rebolo e com a profundidade de corte. É definida como sendo a quantidade de cavaco removida por unidade de tempo e por unidade de área de contato entre a peça e o rebolo. 


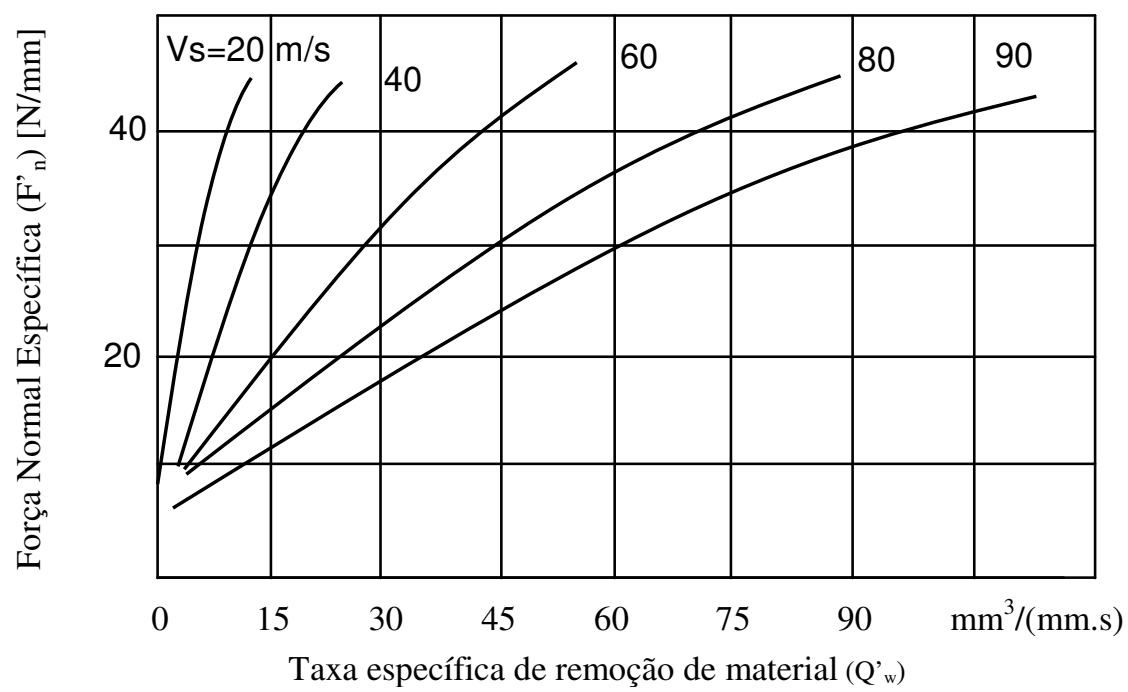

Figura 7. Influência da taxa específica de remoção de material na força normal de corte. Adaptado de Konig (1980).

Para este estudo é importante destacar que a força normal de corte aumenta com o aumento da taxa específica de retificação, e esta por sua vez é proporcional à velocidade de avanço do rebolo sobre a peça (KONIG, 1980) conforme é evidenciado na Figura 7. A rugosidade também mantém uma relação direta com a taxa específica de retificação, o que é mostrado na Figura 8.

2.3.2.3 Influência do desgaste radial do rebolo

O desgaste do rebolo se caracteriza pela perda das arestas cortantes e pelo entupimento dos poros existentes na estrutura, conforme ilustrado na Figura 9. 


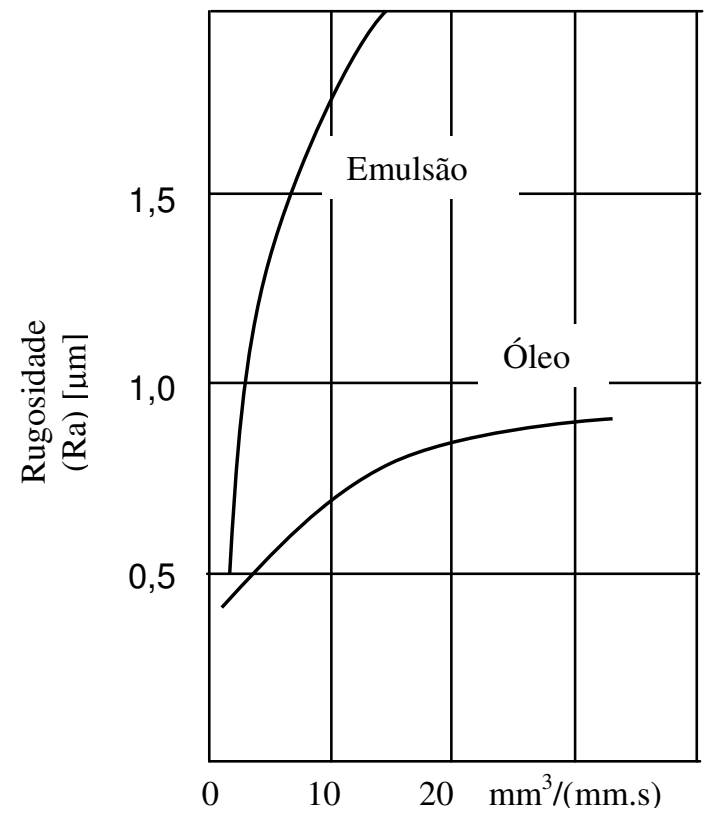

Taxa específica de remoção de material (Q' $\left.{ }_{w}\right)$

Figura 8. Influência da taxa especifica de retificação na rugosidade. Adaptado de Konig (1980).

\section{GRÃOS DO REBOLO}

\section{APÓS A DRESSAGEM \\ ANTES DA DRESSAGEM}

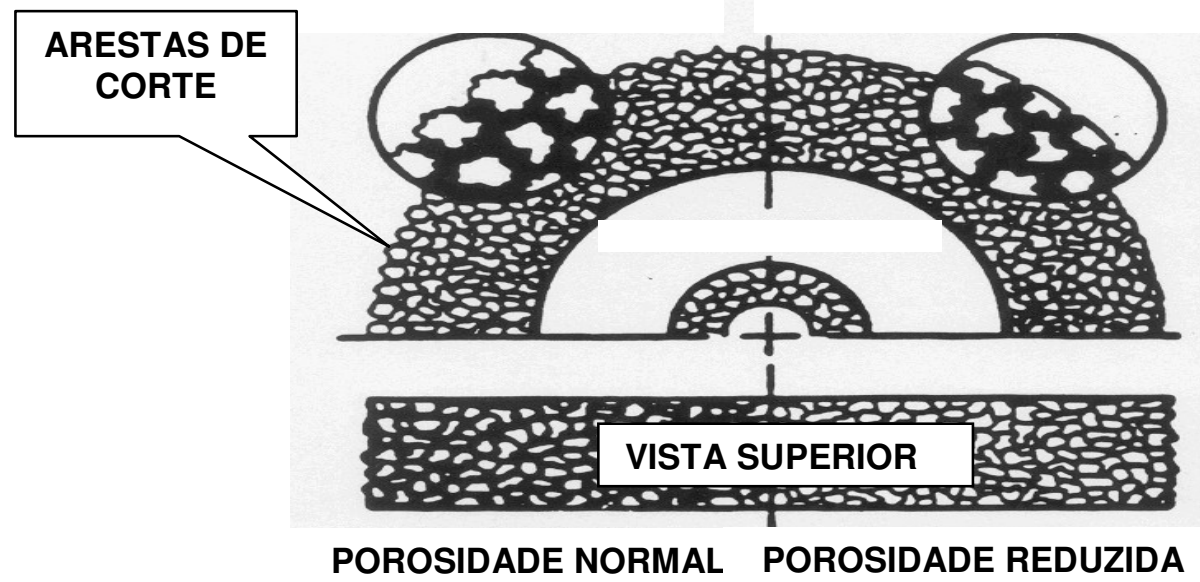

Figura 9. Comparativo entre o rebolo antes e após a dressagem. CINCINNATI MILACRON (1996) 
Isso causa um aumento na força normal, de forma diretamente proporcional (KONIG, 1980).

Para restauração das arestas cortantes do rebolo recorre-se ao processo de dressagem. As condições de dressagem influem no desempenho do processo de usinagem. As variáveis influenciadas pela dressagem são: força de corte, deformação da máquina, geração de calor, rugosidade, erros de forma, acuracidade dimensional e posição do jato do fluído de corte.

Konig (1980) define o grau de recobrimento $\mathrm{U}_{\mathrm{d}}$ como um parâmetro de dressagem, como mostrado na Figura 10:

$$
\mathrm{U}_{\mathrm{d}}=\mathrm{b}_{\mathrm{d}} / \mathrm{S}_{\mathrm{d}} \quad \text {; onde: }
$$

$b_{d}=$ largura de atuação do dressador e $S_{d}=$ passo de dressagem

Grau de recobrimento pequeno, isto é, próximo da unidade, apresenta alta agressividade do rebolo, menor força de corte (Figura 11) e alta rugosidade. Conseqüentemente, valores maiores que a unidade apresenta resultados de forma contrária ao citado.

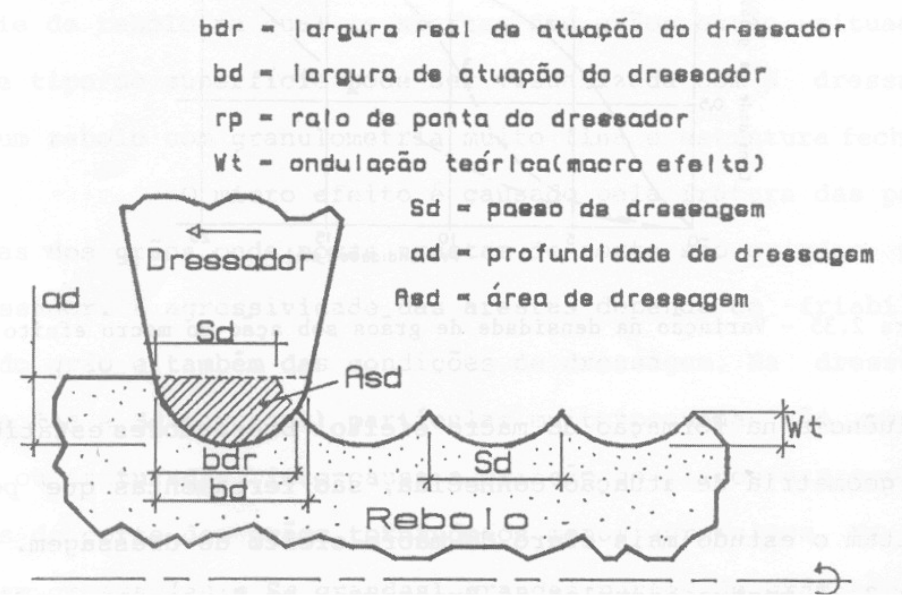

Figura 10. Variáveis influentes no grau de recobrimento. (OLIVEIRA, 1988). 


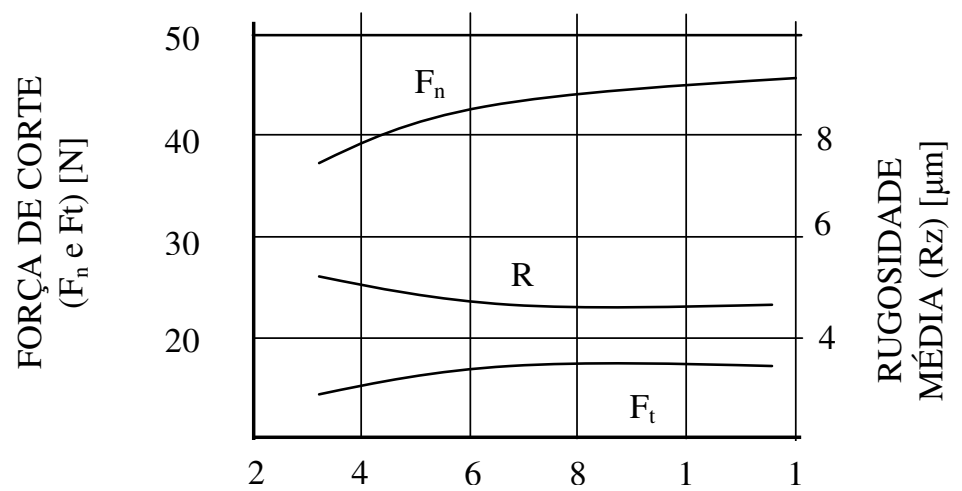

GRAU DE RECOBRIMENTO DE DRESSAGEM U $\mathrm{d}_{\mathrm{d}}$

Figura 11. Influência do grau de recobrimento na força normal de corte. Adaptado de Konig (1980)

O jato do fluído de corte deve ser direcionado diretamente sobre a região da dressagem e enclausurado por um bocal plástico, como sugerido por Cincinnati Milacron (1996) e indicado na Figura 12.

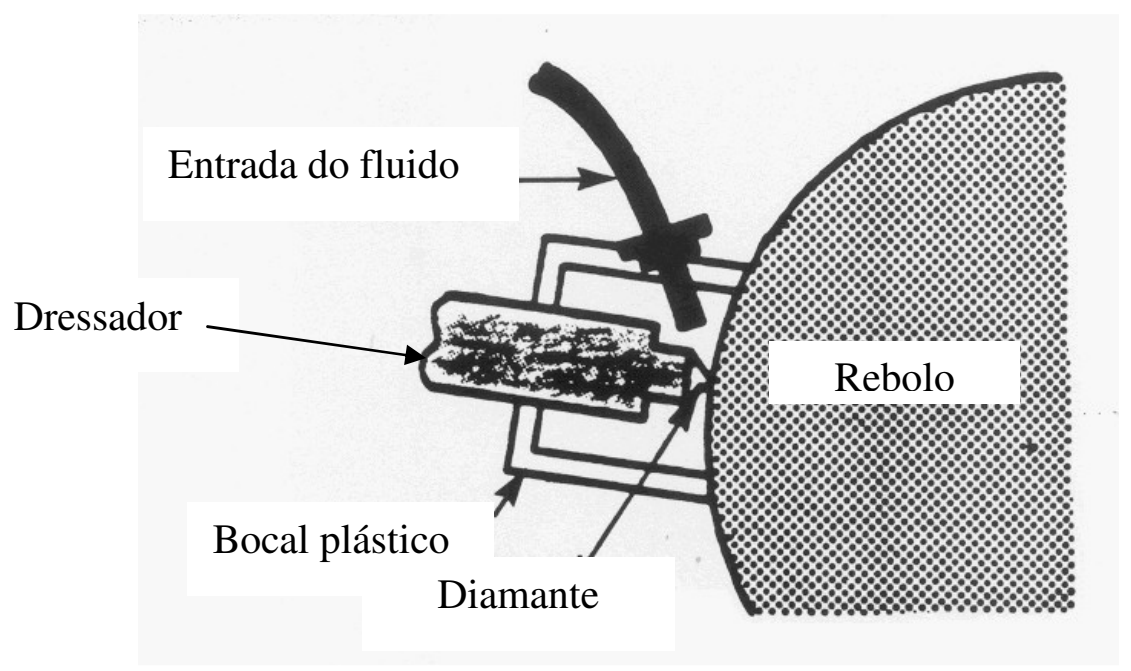

Figura 12. Elementos participantes do processo de dressagem.

(CINCINNATI MILACRON, 1996) 
2.3.2.4 Influência do material da peça

Segundo CINCINNATI MILACRON (1996), o tipo do material da peça tem um impacto significativo no processo de retificação. A dureza é um indicativo da resistência à penetração do grão abrasivo na superfície da peça. A força requerida para ocorrer essa penetração é proporcional à dureza dureza. Um incremento altamente significativo ocorre para peças com dureza acima de $60 \mathrm{HRc}$, conforme pode ser observado na Figura 13.

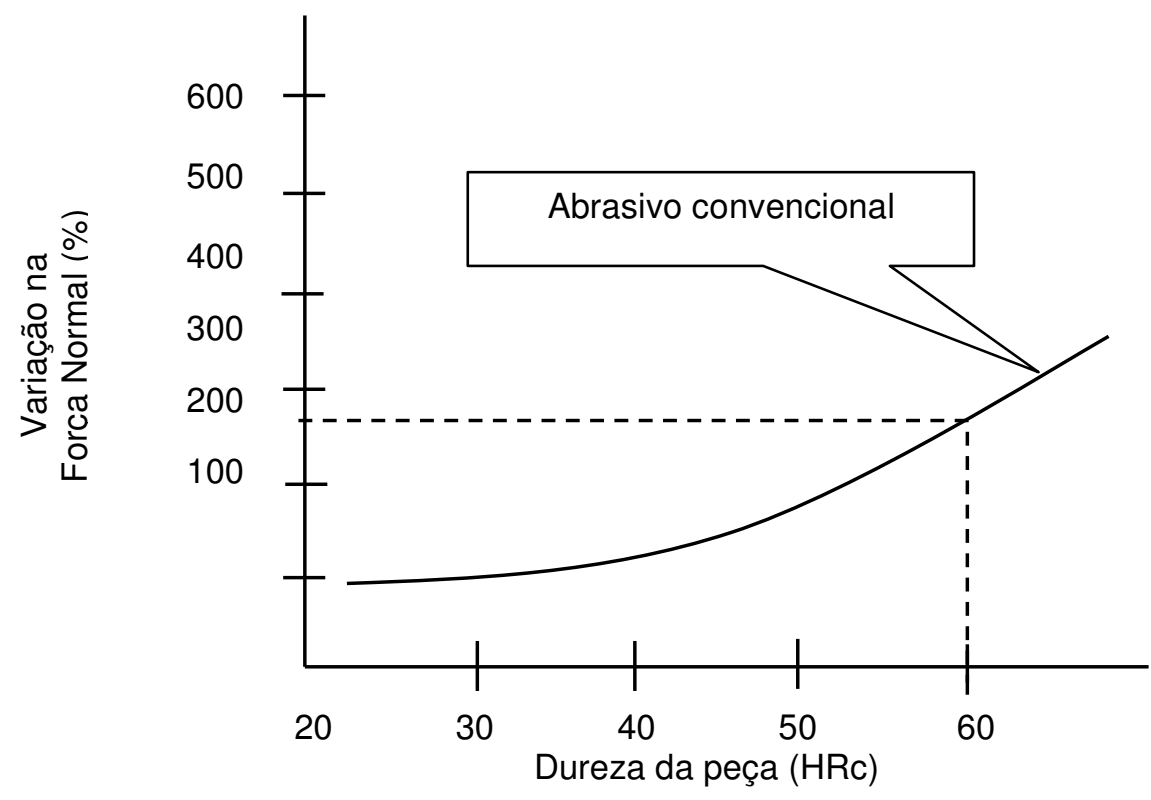

Figura 13. Influência da dureza da peça na força normal de corte. Adaptado de CINCINNATI MILACRON (1996)

\subsubsection{Influência do tempo de spark-out}

Quando for cessado o avanço do rebolo sobre a peça tem inicio a fase de spark-out. Nesse instante o sistema RMP está sob tensão devido à ação da força normal de corte agindo durante o avanço do rebolo. Iniciado o spark-out o sistema começa a se acomodar retomando sua forma original, e assim, a força normal de corte começa a decrescer 
até se anular (KONIG, 1980).

Nessa fase também fica definida a rugosidade da peça - quanto maior o tempo de spark-out, menor será a rugosidade superficial.

Observando-se a Figura 14, fica evidenciado que para um tempo de spark-out mais longo a força de corte é menor, para uma mesma taxa específica de retificação.

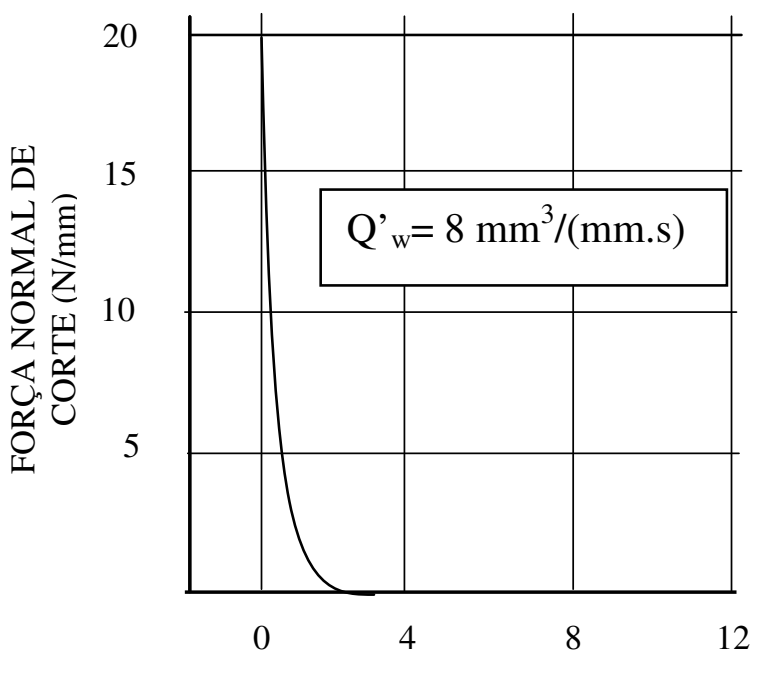

TEMPO DE FAISCAMENTO (s)

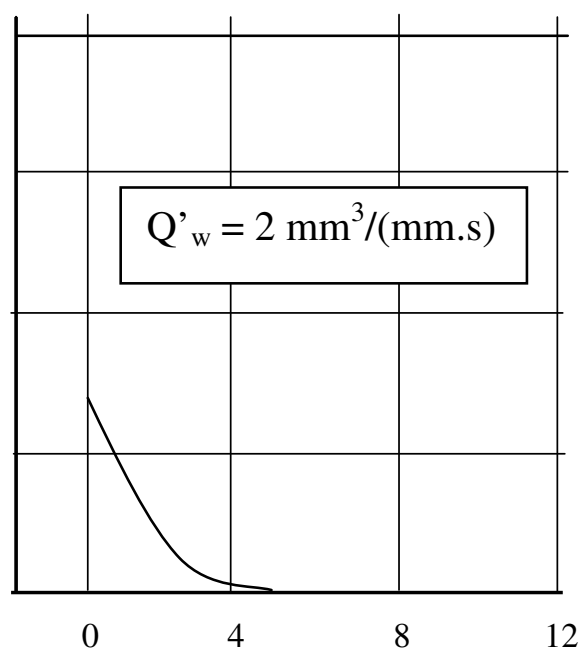

TEMPO DE FAISCAMENTO (s)

Figura 14. Influência do tempo de faiscamento na força normal de corte. Fonte: Adaptado de Konig (1980). 


\section{CAPABILIDADE APLICADA A PROCESSOS}

\section{DE USINAGEM}

Define-se a Análise de Capabilidade do Processo como sendo um estudo de engenharia para estimar a capacidade de um processo de manter suas especificações dentro de parâmetros pré-determinados e de maneira uniforme ao longo do tempo.

Os índices e as taxas que medem a capabilidade surgiram dos estudos sobre Controle Estatístico de Processo (CEP) realizados pelo Dr. Walter Shewhart do Bell Laboratories na década de 20 . Seu surgimento se confunde com o próprio nascimento da área de qualidade, afinal o trabalho inicial realizado no Bell Laboratories foi a base das principais técnicas e ferramentas que fariam nascer nas empresas americanas os departamentos de qualidade durante a segunda guerra (AMARAL; ROSENFELD, 2006).

\subsection{CONCEITUAÇÃO DE ERRO}

As dimensões de uma peça sempre apresentarão erros, ou seja, a medida realizada nunca será igual à medida nominal. Os erros consistem em uma somatória de outros erros de diversas origens que citaremos a seguir, portanto para se produzir um lote de peças dentro de um campo de tolerância exigido, é necessário que se tenha um nível de certeza sobre a estabilidade deste processo.

Denomina-se erro total à diferença entre a dimensão desejada e a dimensão obtida. A redução de erros a níveis pequenos na fase de projeto, requer custos impraticáveis 
na fase de execução do processo. Ainda a redução de erros é reduzida com a construção de máquinas estruturalmente corretas, com distribuição ideal de massas, órgão de máquinas extremamente precisos, materiais com coeficiente de dilatação próximo de zero, requer pessoal extremamente qualificados, tempo e equipamentos sofisticados (MEDALHA, 2001).

\subsubsection{ERROS GEOMÉTRICOS}

As máquinas-ferramentas são constituídas por mesas, guias, fusos, eixos e outras estruturas.

São denominados erros geométricos aqueles oriundos da geometria da máquina, que causam movimentos indesejáveis entre os seus componentes provocando erro na dimensão e na geometria das peças fabricadas. Em máquinas-ferramentas, estes deslocamentos indesejáveis acabam modificando o posicionamento previsto da ponta da ferramenta e a posição da usinagem, acarretando o que se convencionou chamar de erro total.

\subsubsection{ERROS DE MÁQUINA}

São aqueles que causam erros na posição relativa entre a peça e a ferramenta e variam lentamente com o passar do tempo (SLOCUM, 1992). Esse mesmo autor classifica esses erros em:

a) Erros de Carregamentos 
Podem ter origem devido ao peso próprio da máquina ou devido ao peso da peça a ser usinada, causando deflexões na estrutura. A distribuição do peso da máquina e do peso da peça sobre a máquina não é homogênea o que pode causar deslocamentos na estrutura devido a deslocamento do cabeçote, carros, montagem de dispositivos, etc.

b) Erros termicamente induzidos

São aqueles originados pela variação da temperatura da máquina. Os erros térmicos, assim chamados têm origens diversas, como:

b.1 - Influencias do ambiente

Incluí as variações de temperatura onde está localizada a máquina. Depende da existência de climatização do ambiente, da temperatura do ar ambiente, e do calor gerado por outras máquinas instaladas nas proximidades.

\section{b.2 - Sistema de refrigeração}

Os fluidos que circulam pela estrutura da máquina distribuem e alteram a temperatura das partes da estrutura. Se o sistema de refrigeração não for eficaz, pode haver um aquecimento excessivo em partes da estrutura da máquina e da peça promovendo, assim, variações no posicionamento relativo entre a peça e a ferramenta. 


\section{b.3 - Pessoas}

A presença de pessoas nas proximidades da máquina contribui para a alteração da temperatura, o que também muda o posicionamento relativo entre a peça e a ferramenta.

$$
\text { b.4 - Proximidade de outra máquinas }
$$

A presença de outras máquinas nas proximidades transfere calor influindo termicamente no processo. Essa transmissão pode ser por meio de radiação e convecção.

$$
\text { b.5 - Processo de usinagem }
$$

Durante o processo de usinagem há geração de calor devido ao atrito e deformação do cavaco.

A qualidade de uma máquina está relacionada com sua capacidade de gerar componentes mecânicos com geometria e dimensões finais o mais próximo possível das planejadas. No entanto, devido a problemas que são inerentes aos sistemas que compõe uma máquina, o correto posicionamento de todos os seus elementos de fixação é alterado provocando assim desvios nas dimensões das peças obtidas.

Para aumentar a acuracidade de uma máquina-ferramenta podem-se utilizar dois métodos. O primeiro relaciona-se com as modificações nos elementos físicos da máquina, enquanto o outro se resume em minimizar os problemas existentes através de programas computacionais.

No primeiro caso está incluído o aumento da precisão mecânica dos elementos 
da máquina ou as modificações nos elementos já construídos. Tais soluções normalmente não são facilmente aceitas devido aos seguintes fatores:

a) Os custos para construir elementos de grande precisão, em geral, são maiores do que as vantagens alcançadas com sua utilização;

b) Modificações nas máquinas que já estão em funcionamento tornam-se difíceis de serem implementadas devido às limitações técnicas.

No segundo caso está a compensação de erros através de programas computacionais com o objetivo de minimizar erros existentes em máquinas ferramentas. Através de programas de compensação é possível manter a precisão das peças usinadas dentro de níveis bastante razoáveis a um custo razoável (MEDALHA, 2001).

Sistemas de medição em processo, comerciais, podem ser utilizados na obtenção dessas informações. Porém, essa alternativa se torna prejudicada pela necessidade de flexibilidade, pois a variação geométrica e dimensional das peças exige que o sistema seja ajustado a cada de produto e sistema auto-ajustáveis apresentam custos elevados. Por outro lado, devido a grande acuracidade desejada, esses sistemas necessitam de calibração para o seu funcionamento, o que implica em aumento do tempo de máquina parada.

Seja qual for o caso adotado, o monitoramento do resultado deve ser feito e para isso um estudo da capabilidade do processo deve ser utilizado. Alguns fatores que influem no estudo da capabilidade devem ser observados e serão descritos a seguir.

\subsection{INFLUÊNCIAS NA CAPABILIDADE EM PROCESSOS DE RETIFICAÇÃO}

Alguns aspectos influem na capabilidade do processo, como se passa a descrever: 


\subsubsection{DESGASTE DO REBOLO}

Existe uma grande tendência, em retificação de precisão, de se adotar rebolos mais duros para se obter melhor acabamento e manter essa característica pelo tempo mais longo possível. As características destes rebolos, aliada à pequena quantidade de material retirado na fase de acabamento, contribui para que o seu desgaste seja minimizado. Com isso é possível obter uma capabilidade do processo mais estável (KONIG, 1980).

\subsubsection{DEFORMAÇÃO DA MÁQUINA}

Num processo de retificação cilíndrica transversal, quando o rebolo avança sobre a peça durante a usinagem, as forças envolvidas provocam deformações na estrutura da máquina. Na fase de centelhamento ou spark-out, quando o rebolo deixa de avançar, a tensão acumulada faz com que este ainda avance um pouco mais devido á deformação elástica do sistema rebolo-máquina-peça (RMP). Com isso, ainda um pouco mais de material é removido e a deformação causada pelas forças de corte é minimizada. A estabilidade do processo é influenciada por essas deformações e devem ser medidas e monitoradas (KONIG, 1980).

\subsection{CLASSIFICAÇÃO DAS VARIAÇÕES EM PROCESSO}

A variação dimensional no processo de retificação pode ter duas origens: 


\subsubsection{VARIAÇÃO NATURAL, ALEATÓRIA OU RANDÔMICA}

Essa variabilidade ocorre em função de características próprias do processo, geralmente está associada a erros aleatórios de leitura. Esta variação não pode ser eliminada, somente reduzida. É resultado de influencias externas e internas, não controladas, que provocam o aparecimento de erros não repetitivos, em geral diferem para cada leitura, podendo-se apenas ter noção de seus limites. Tais erros somente podem ser avaliados estatisticamente. Em muitos casos assume-se que os erros aleatórios são normalmente distribuídos. Mesmo que sejam mantidas constantes todas as variáveis externas e internas durante a realização dos testes, os erros aleatórios estarão sempre presentes, provocando variações em medições sucessivas (MONTGOMERY, 1985).

\subsubsection{VARIAÇÃO SISTEMÁTICA}

Segundo Montgomery (1985), ocorre uma variação em função do tempo. Normalmente é regida por uma regra que se repete ou se mantém constante com o tempo. Estes erros permanecem constantes em grandeza e sinal ou mesmo variam de acordo com uma lei definida, quando um número considerável de medições de um mesmo valor é efetuado sob as mesmas condições. Uma vez determinados, ocorrem de maneira previsível em todo o trabalho da máquina.

Ainda, segundo os mesmos autores, o conhecimento da capabilidade de um processo tem grande aplicação em diversas atividades na indústria. É de vital importância para:

- Estudar os processos durante o seu desenvolvimento, ou seja, antes do inicio da fabricação. 
- Prever o quanto um processo se manterá dentro das tolerâncias especificadas.

- Auxiliar a fabricação na redução ou eliminação dessa variação.

- Avaliar esta variação em função das especificações do produto.

- Especificar o desempenho de um novo equipamento.

- Definir um entre vários fornecedores de uma máquina.

\subsection{EXPRESSÃO DA CAPABILIDADE}

Uma forma de expressar a capabilidade de um processo é através do cálculo do índice de Capabilidade do Processo (Cp). Dentre outros existentes, será detalhado o que será adotado ao longo deste trabalho.

Para aplicação desta técnica estatística faz-se necessário que o processo esteja sob controle estatístico, isto é, que não existam causas especiais influenciando a variação, mas somente causas comuns (AMARAL; ROZENFELD, 2006).

Causa especial: a variação é intermitente, normalmente imprevisível e instável, também conhecido como ruído no processo. Caracteriza-se por um ponto fora dos limites esperados.

Causa comum: aquela que afeta todos os pontos que estão sendo estudados.

Numa distribuição normal, caracterizada por uma média $(\varphi)$ e um desvio padrão ( $\sigma$ ), segundo Amaral e Rozenfeld, (2006) considera-se:

Limite Superior Especificado (LSE)

Limite Inferior Especificado (LIE), 
Limite Natural de Tolerância Superior (LNTS)

Limite Natural de Tolerância Inferior (LNTI)

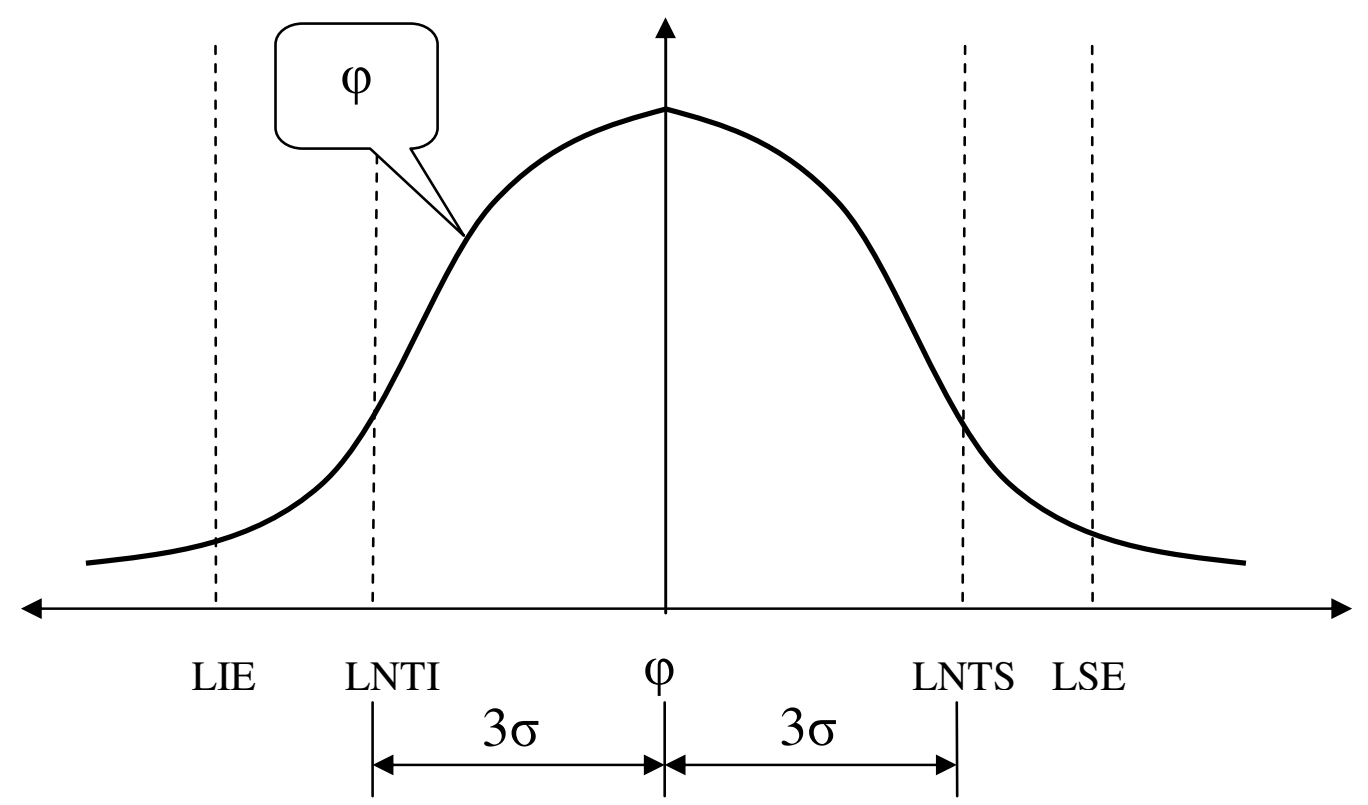

Figura 15. Distribuição normal de uma grandeza qualquer. (AMARAL; ROZENFELD, 2006)

É o mais usual adotar o Limite Natural de Tolerância como aquele delimitado por três desvios padrão $(3 \sigma)$ acima e três abaixo da média. O desvio padrão $(\sigma)$ é estimado considerando-se um processo prévio e estável conhecido, conforme Figura 15.

Ainda, conforme estudos estatísticos sabe-se que $97,3 \%$ dos pontos da amostra estarão dentro dos limites $+/-3 \sigma$ ou por outro lado, $0,27 \%$ dos pontos estarão fora destes limites, correspondendo a 2700 pontos / milhão (MONTGOMERY, 1985).

Segundo Amaral e Rozenfeld (2006), definem-se Capabilidade de Máquina (Cp) como sendo o intervalo de tolerância dividido pela variabilidade do processo, ou seja, 6 vezes o desvio-padrão estimado considerando a ausência de causas especiais. Ele é independente da centralização do processo. O desvio padrão é estimado considerando processos estáveis.

Superior de Capabilidade (Cps): variação superior da tolerância dividida por 
3 vezes o desvio padrão estimado pela capabilidade do processo.

Inferior de Capabilidade (Cpi): variação inferior da tolerância dividida pela dispersão superior real do processo.

Capabilidade (Cpk): é o índice que leva em conta a centralização do processo.

Assim, calcula-se a capabilidade como segue:

$$
\begin{array}{lr}
\mathrm{C}_{\mathrm{p}}=(\mathrm{LSE}-\mathrm{LIE}) / 6 \sigma & \text { distribuição bilateral } \\
\mathrm{C}_{\mathrm{ps}}=(\mathrm{LSE}-\mu) / 3 \sigma & \text { distribuição unilateral superior } \\
\mathrm{C}_{\mathrm{pi}}=(\mu-\mathrm{LSI}) / 3 \sigma & \text { distribuição unilateral inferior } \\
\mathrm{C}_{\mathrm{pk}}=\text { é o menor índice entre os } \mathrm{C}_{\mathrm{ps}} \text { e } \mathrm{C}_{\mathrm{pi}} .
\end{array}
$$

Em função do valor calculado para o índice Cpk, pode-se avaliar a quantidade de peças não-conforme, de acordo com a Tabela 1 (MONTGOMERY, 1985):

Tabela 1 - Valores da Capacidade do Processo e quantidade de não-conformidades para uma distribuição normal. (MONTGOMERY, 1985)

\begin{tabular}{ccc}
\hline \multicolumn{3}{c}{ Não-Conformidades [ppm] } \\
\hline Cpk & Tolerância unilateral & Tolerância bilateral \\
& & 133.600 \\
0,50 & 66.800 & 24.400 \\
1,00 & 12.200 & 2.700 \\
1,10 & 1.350 & 966 \\
1,20 & 483 & 318 \\
1,30 & 159 & 96 \\
1,40 & 48 & 26 \\
1,50 & 13 & 6,80 \\
1,60 & 3,40 & 1,60 \\
1,70 & 0,80 & 0,34 \\
1,80 & 0,17 & 0,06 \\
2,00 & 0,03 & 0,0018 \\
\hline
\end{tabular}




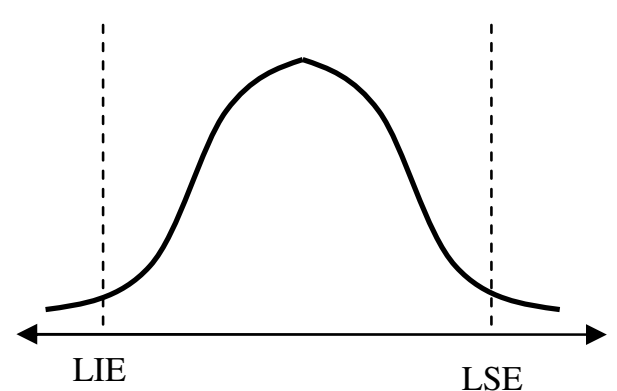

\section{Cp baixo}

Causa: variação maior que a faixa dos limites de especificação

\section{Cpk baixo}

Causa: a distribuição está centrada, mas há uma variação maior que a faixa dos limites de especificação

Processo: incapaz

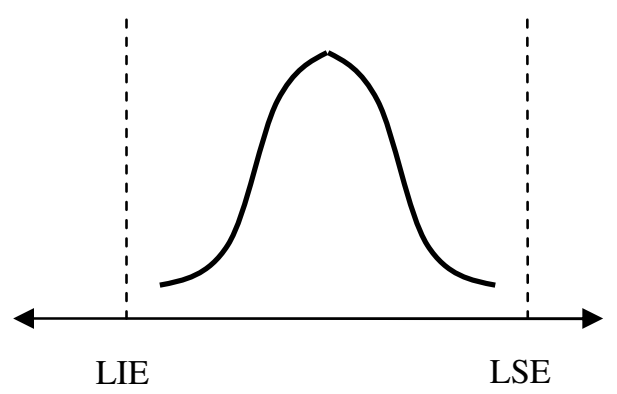

Cp intermediário

A variação é menor que a faixa dos limites de especificação

Cpk intermediário

A distribuição está centrada e há uma variação menor que a faixa dos limites de especificação

Processo: satisfatório

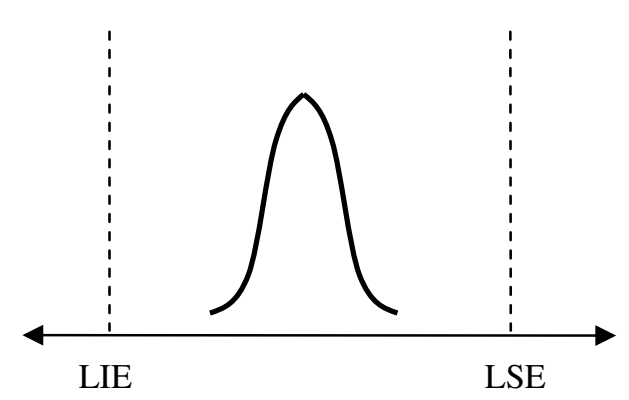

Cp alto

Baixa variação em relação à faixa dos limites de especificação

Cpk alto

A distribuição está centrada e há baixa variação em relação à faixa dos limites de especificação

Processo: capaz

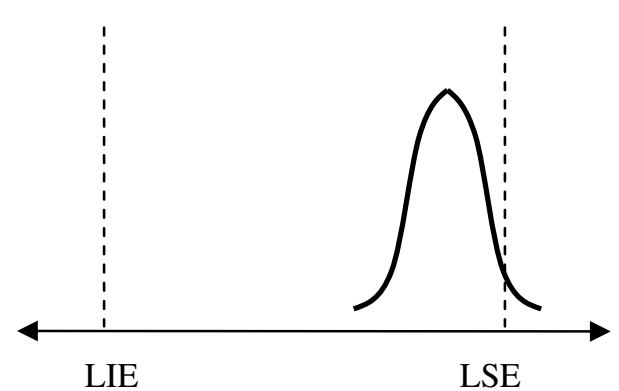

\section{Cp alto}

Baixa variação em relação à faixa dos limites de especificação

\section{Cpk baixo}

Baixa variação em relação à faixa dos limites de especificação e a distribuição não está centrada

Processo: incapaz

Figura 16. Definição do Cp e Cpk em função da dispersão. (DATALYZER, 2007) 
Por fim conclui-se pela capacidade, ou não, do processo em função do índice calculado, conforme apresentado na Figura 16 e descrito a seguir:

$$
\begin{array}{ll}
\text { Cpk }<1 & \text { processo incapaz } \\
1 \leq \quad \mathrm{Cpk} \leq 1,33 & \text { processo intermediário } \\
\mathrm{Cpk}>1,33 & \text { processo capaz }
\end{array}
$$

No entanto o cliente usuário da máquina pode definir outros valores para o Cpk, de acordo com sua necessidade, conforme Tabela 2:

Tabela 2 - . Valores mínimos recomendados para Índice de Capabilidade do Processo (Cpk). (MONTGOMERY, 1985)

\begin{tabular}{lcc}
\hline & Tolerância unilateral & Tolerância bilateral \\
\hline Processos existentes & 1,25 & 1,33 \\
$\begin{array}{l}\text { Novos processos } \\
\text { Segurança, parâmetros } \\
\text { críticos para processos }\end{array}$ & 1,45 & 1,50 \\
$\begin{array}{l}\text { existentes } \\
\begin{array}{l}\text { Segurança, parâmetros } \\
\text { críticos para novos processos }\end{array}\end{array}$ & 1,45 & 1,50 \\
\hline
\end{tabular}

Um processo deve produzir peças dentro da tolerância especificada e ainda manter um nível de variação uniforme suficientemente bom, ou aceitável.

$\mathrm{Na}$ especificação de um processo normalmente inclui-se a tolerância dimensional (aqui simplesmente denominado Tolerância) como sendo a diferença entre o Limite Superior Especificado e o Limite Inferior Especificado e ainda o Índice de Capacidade do Processo (Cp).

$$
\begin{aligned}
& \mathrm{Cp}=(\mathrm{LSE}-\mathrm{LIE}) / 6 \sigma \quad, \text { ou seja, } \\
& \mathrm{Cp}=\text { Tolerância } / 6 \sigma
\end{aligned}
$$

Assim, um equipamento para atender satisfatoriamente a especificação da 
tolerância e da dispersão do processo deve manter as dimensões dentro do campo correspondente a $6 \sigma$ e centralizado. 


\section{METODOLOGIA}

\subsection{FORMULAÇÃO DO PROBLEMA}

O trabalho de laboratório teve como premissa que o processo foi realizado em condição normal de produção, assim utilizou-se um rebolo duro, de modo que o desgaste seja desprezível. O regime de trabalho é permanente, isto é, a temperatura de trabalho permanece constante durante o experimento. A refrigeração é suficiente para o processo considerado.

Já foi demonstrado por diversos pesquisadores como Tlusty (1970), Malkin (1980) e Lichun (1980) apud Oliveira (1988), que a velocidade de avanço na retificação influi proporcionalmente na deformação do sistema RMP, e este por sua vez influencia no diâmetro final da peça. Assim o problema fica estabelecido, ou seja, confirmar a existência de uma relação direta entre a capabilidade da máquina e o diâmetro especificado para a peça a ser usinada. Isto será feito ao longo desta pesquisa.

Dessa forma foi estabelecida a seguinte hipótese, com aplicação do método dedutivo:

1 - A deformação numa máquina (no caso desta pesquisa) é proporcional à força exercida sobre a sua estrutura (lei de Hooke).

2 - A força radial existente entre o rebolo e a peça durante a usinagem é proporcional à velocidade de avanço (KONIG, 1980) e (TLUSTY, 1980).

3 - A deformação da máquina é proporcional à velocidade de avanço (já detalhado no item 2.2.1). 
4 - Neste trabalho será demonstrado que a variação dimensional da peça é proporcional à deformação da máquina e esta, por sua vez, é proporcional à velocidade de avanço (deduzido na alínea 3).

\subsection{CARACTERIZAÇÃO DO PROCEDIMENTO E DOS EQUIPAMENTOS UTILIZADOS}

Foi adotada uma configuração de retificação tangencial externa de mergulho devido à sua larga aplicação nas indústrias e por apresentar relativa simplicidade, quando comparado aos outros processos de retificação.

\subsubsection{MÁQUINA-FERRAMENTA / INSTRUMENTOS}

O equipamento utilizado neste ensaio foi disponibilizado pelo NUMA (Núcleo de Manufatura Avançada) da EESC USP.

Foi utilizada uma retificadora cilíndrica externa entre centros, marca Zema modelo Numerika G-800-HS.

Para medição do diâmetro das peças utilizou-se um micrometro digital Tesa $25-50 \mathrm{~mm}$.

\subsubsection{CORPOS-DE-PROVA}


Os corpos-de-prova tinham diâmetro nominal de $47 \mathrm{~mm}$ e comprimento $80 \mathrm{~mm}$, material: aço para beneficiamento SAE 4340, temperado, dureza $52 \mathrm{HRc}$, conforme ilustrado na Figura 17.

Visando-se minimizar o efeito da influência da deformação da peça na rigidez do sistema RMP optou-se pela utilização de uma peça de maior diâmetro, curta, com fixação em placa de três castanhas com apoio no contraponto.

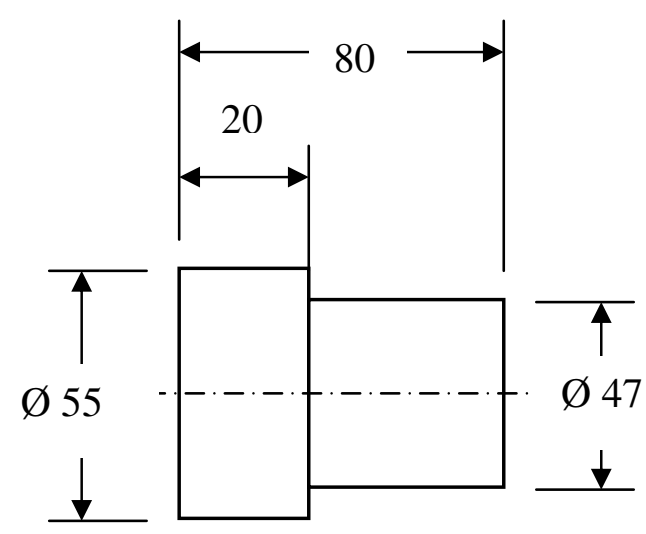

Figura 17. Corpo-de-prova utilizado nos ensaios. Dimensões em mm.

\subsubsection{CONDIÇÕES DE DRESSAGEM / SISTEMA DE DRESSAGEM}

As dressagem foram feitas a cada inicio de novo lote de peças a serem retificadas. Foram feitas com um dressador estático com diamante de ponta única. As dimensões da ponta do dressador foram medidas num projetor de perfis. As condições de dressagem são caracterizadas pelo índice denominado grau de recobrimento $\left(\mathrm{U}_{\mathrm{d}}\right)$ (OLIVEIRA, 1988), definido como a relação entre a largura de atuação do dressador $\left(b_{d}\right)$ e o passo de dressagem $\left(\mathrm{S}_{\mathrm{d}}\right)$. 


$$
\left.\begin{array}{l}
\mathrm{b}_{\mathrm{d}}=0,9 \mathrm{~mm} \\
\mathrm{~S}_{\mathrm{d}}=0,9 \mathrm{~mm} / \text { rotação }
\end{array}\right\} \quad \begin{aligned}
& \mathrm{Ud}=\mathrm{b}_{\mathrm{d}} / \mathrm{S}_{\mathrm{d}}=0,9 /, 09=> \\
& \mathrm{Ud}=1 \text { (grau de recobrimento utilizado) } \\
& \mathrm{Vt}=1500 \mathrm{~mm} / \mathrm{min} \\
& \mathrm{a}_{\mathrm{d}}=0,010 \mathrm{~mm}
\end{aligned}
$$

\subsubsection{FLUIDO DE CORTE}

O fluido de corte utilizado é de origem vegetal biodegradável.

Antes do inicio dos ensaios, a máquina, o fluído de corte, o rebolo e o sistema hidráulico foram mantidos ligados por 30 min a fim de se obter uma estabilização térmica.

\subsubsection{FERRAMENTA DE CORTE}

Foi utilizado um rebolo de óxido de alumínio 38-A-80-KVHB, Ø $508 \mathrm{~mm}$ e largura $50 \mathrm{~mm}$. A taxa especifica de remoção de material ( $\left.\mathrm{Q}_{\mathrm{w}}{ }^{\prime}\right)$ desse rebolo, especificado pelo fabricante, é Q'= $100 \mathrm{~mm}^{3} /($ min.mm). A largura de corte adotada foi de $15 \mathrm{~mm}$. 


\subsection{PROCEDIMENTOS PARA VERIFICAÇÃO DA RELAÇÃO ENTRE O TEMPO DE SPARK-OUT E O DIÂMETRO FINAL DA PEÇA.}

Essa atividade de laboratório foi feita com ciclo de retificação em mergulho. A velocidade de avanço máxima em mergulho (Vf) foi determinada observando-se a potência consumida pelo motor durante a usinagem, assim para uma potência de $95 \%$ a velocidade obtida foi de $2,5 \mathrm{~mm} / \mathrm{min}$, considerando-se uma largura de retificação de $15 \mathrm{~mm}$. A rotação da peça foi ajustada para $200 \mathrm{rpm}$.

Para este ensaio foram disponibilizadas seis peças. Cada uma delas foi fixada na placa de três castanhas do cabeçote porta-peça e anotada a posição em que coincide com uma determinada castanha a fim de permitir sua fixação sempre na mesma referência, conforme Figura 18. A seguir foi dado um passe de $0,020 \mathrm{~mm}$ para regularização das superfícies.

Cada uma destas peças, antes da usinagem, foi novamente fixada na placa e apoiada no contraponto da máquina, fazendo-se coincidir com a mesma posição anterior em relação à placa.

Fixada a primeira peça foi feito a aproximação do rebolo manualmente até que se observasse visualmente o inicio de centelhas. A partir deste ponto o rebolo foi afastado da peça a uma distancia de $100 \mathrm{~mm}$, controlado pelo CNC da máquina, estabelecendo-se esta como a posição referencial do rebolo antes do inicio de cada usinagem. 


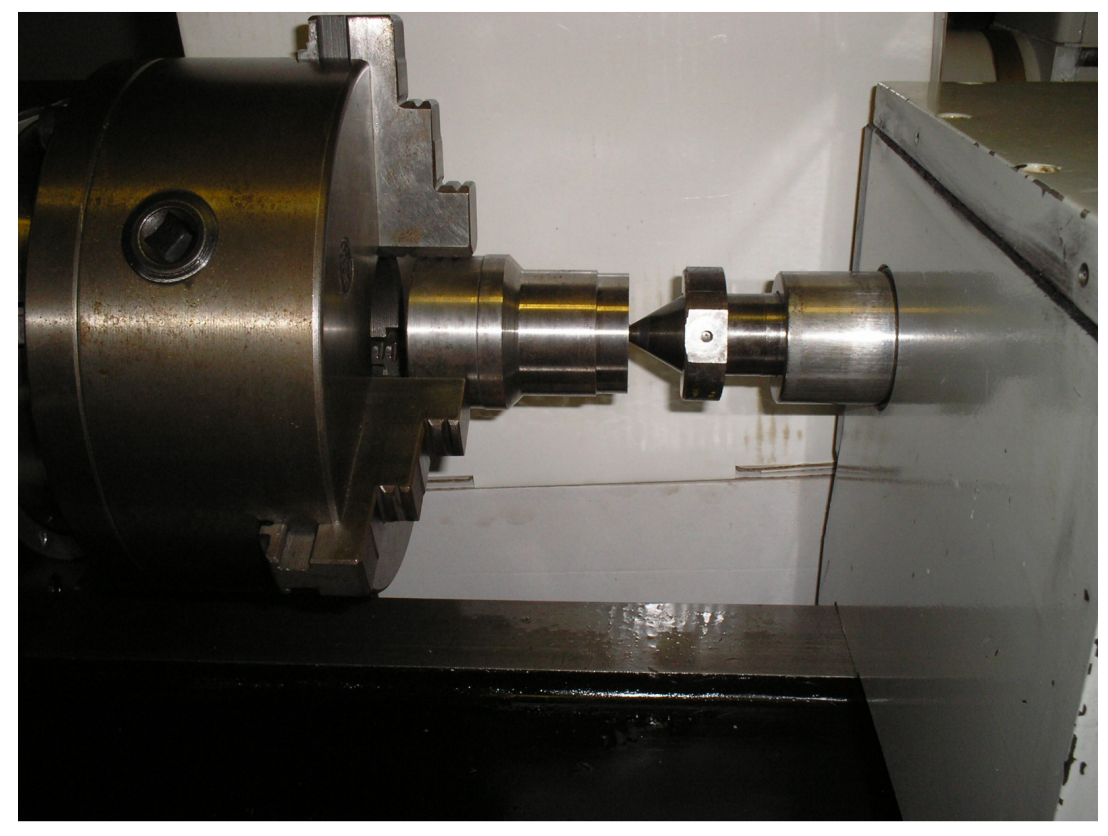

Figura 18. Detalhe mostrando a peça fixada na máquina

Dando inicio ao ensaio, a máquina foi ajustada para um ciclo sem spark-out, sobremetal de $0,200 \mathrm{~mm}$ e velocidade de avanço $\mathrm{V}_{\mathrm{f}}=2,5 \mathrm{~mm} / \mathrm{min}$. Foram medidos os diâmetros de cada peça antes e após a usinagem, cuja diferença foi anotada como $\Delta \emptyset$. Assim repetiu-se o ciclo de usinagem para cada peça. A primeira peça foi usinada sem spark-out e as seguintes tiveram um incremento de tempo de spark-out de 1 segundo sucessivamente.

Observou-se existir uma relação diretamente proporcional, não linear, apresentado entre o tempo de spark-out e a quantidade de metal removido, conforme Tabela 3.

Tabela 3 - Relação entre o tempo de spark-out e a redução no diâmetro $(\Delta \emptyset)$ medida. Dimensões em mm.

\begin{tabular}{ccccccc}
\hline Peça $\mathrm{n}^{\circ}$ & 1 & 2 & 3 & 4 & 5 & 6 \\
\hline Spark-out (s) & 0 & 1 & 2 & 3 & 4 & 5 \\
\hline$\varnothing \mathrm{i}$ & 47,533 & 47,206 & 44,540 & 44,285 & 44,206 & 43,765 \\
\hline$\varnothing \mathrm{f}$ & 47,348 & 47,011 & 44,342 & 44,086 & 44,006 & 43,565 \\
\hline$\Delta \varnothing(\mathrm{a})$ & 0,185 & 0,195 & 0,198 & 0,199 & 0,200 & 0,200 \\
\hline$\Delta \varnothing$ (b) programado & 0,200 & 0,200 & 0,200 & 0,200 & 0,200 & 0,200 \\
\hline Diferença (b)-(a) & 0,015 & 0,005 & 0,002 & 0,001 & 0 & 0 \\
\hline
\end{tabular}


Nota-se que para um maior tempo de spark-out o material removido tende a se aproximar do sobremetal programado no $\mathrm{CNC}$ da máquina. Isto mostra que houve tempo suficiente para a máquina retornar à sua forma original, compensando a deformação ocorrida durante o avanço, evidenciada na Figura 19.

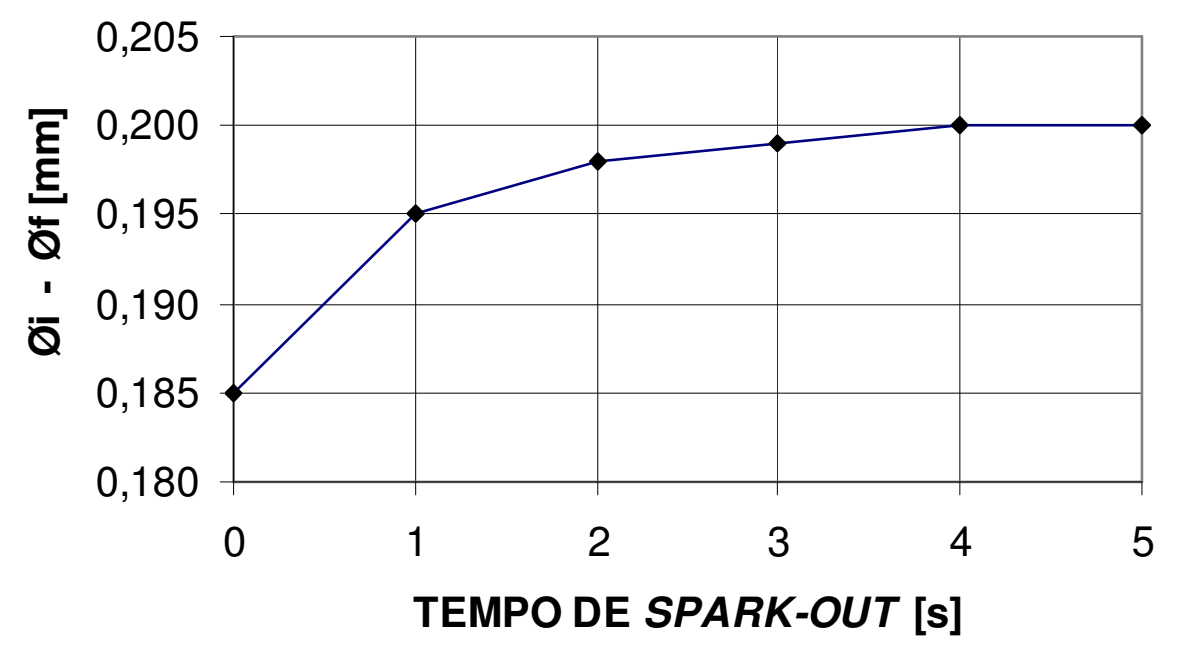

Figura 19 Influência do tempo de spark-out (faiscamento) no diâmetro da peça após a usinagem. Plotagem dos dados informados na Tabela 3.

\subsection{PROCEDIMENTOS PARA VERIFICAÇÃO DA RELAÇÃO ENTRE A VELOCIDADE DE AVANÇO E A DEFORMAÇÃO DA MÁQUINA}

No item 2.2.1, onde foi apresentado o método de Tlusty, foi deduzida a expressão (6) onde $F_{n}=f\left(V_{f}\right)$. Segundo a lei de Hooke, a deformação é diretamente proporcional à força aplicada, e como a força aplicada é proporcional à Velocidade de Avanço $\left(\mathrm{V}_{\mathrm{f}}\right)$, então conclui-se que a deformação da máquina é proporcional à Velocidade de Avanço $\left(\mathrm{V}_{\mathrm{f}}\right)$ do rebolo sobre a peça. No ensaio descrito a seguir foi verificada a veracidade desta 
relação.

Para este ensaio foram disponibilizadas sete peças. Da mesma forma anterior, cada uma das peças foi fixada na placa de três castanhas do cabeçote porta-peça e anotada a posição em que coincide com uma determinada castanha a fim de permitir sua fixação sempre na mesma referência. A seguir foi dado um passe de $0,020 \mathrm{~mm}$ para regularização das superfícies.

Cada uma das peças foi novamente fixada na placa fazendo-se coincidir com a mesma posição anterior em relação à placa.

Fixada a primeira peça foi feito a aproximação do rebolo manualmente até que se observasse visualmente o inicio de centelhas. A partir deste ponto o rebolo foi afastado da peça a uma distancia de $100 \mathrm{~mm}$, estabelecendo-se esta como a posição referencial do rebolo antes de iniciar as usinagens.

Para cada uma das sete peças foi ajustado o tempo de spark-out para zero segundo e, nesse caso, um sobremetal de $0,050 \mathrm{~mm}$. As velocidades de avanço $\left(\mathrm{V}_{\mathrm{f}}\right)$ foram crescentes para cada uma das peças, variando de 0,1 a $2,5 \mathrm{~mm} / \mathrm{min}$, com incremento de 0,4 mm/min. Para cada peça usinada foram medidos e anotados os diâmetros antes e após a operação de retificação por mergulho, obtendo-se assim, a variação sofrida no diâmetro $(\Delta \emptyset)$.

Aplicando-se o mesmo procedimento, essas mesmas peças foram novamente usinadas, agora com tempo de spark-out de 10 segundos. Os resultados obtidos estão apresentados na Tabela 4 .

Para todas as peças usinadas observou-se uma diferença na quantidade de material removido quando se considera a peça com tempo de spark-out $10 \mathrm{~s}$ ou sem sparkout. Isto foi evidenciado pela variação no diâmetro das peças. 
Tabela 4 - Dimensões obtidas na usinagem sem spark-out e com spark-out $10 \mathrm{~s}$.

\begin{tabular}{|c|c|c|c|c|c|c|c|c|}
\hline & & \multicolumn{3}{|c|}{---------Spark-out 0--------- } & \multicolumn{3}{|c|}{--------Spark-out 10------ } & Deformação \\
\hline Peça no & $\begin{array}{c}\mathrm{Vf} \\
(\mathrm{mm} / \mathrm{min})\end{array}$ & $\varnothing \mathrm{i}$ & $\varnothing f$ & $\begin{array}{c}\Delta \emptyset_{\mathrm{o}} \\
(\varnothing \mathrm{i}-\varnothing \mathrm{f})\end{array}$ & $\varnothing \mathrm{i}$ & $\varnothing f$ & $\begin{array}{c}\Delta \emptyset 10 \\
(\emptyset \mathrm{i}-\varnothing \mathrm{f})\end{array}$ & $\begin{array}{c}\Delta \emptyset \\
\left(\Delta \emptyset_{0}-\Delta \emptyset 10\right)\end{array}$ \\
\hline 1 & 0,1 & 47,486 & 47,294 & 0,192 & 47,252 & 47,053 & 0,199 & 0,007 \\
\hline 2 & 0,5 & 47,028 & 46,836 & 0,192 & 43,993 & 43,793 & 0,200 & 0,008 \\
\hline 3 & 0,9 & 46,519 & 46,328 & 0,191 & 46,312 & 46,112 & 0,200 & 0,009 \\
\hline 4 & 1,3 & 46,096 & 45,907 & 0,189 & 45,881 & 45,681 & 0,200 & 0,011 \\
\hline 5 & 1,7 & 45,654 & 45,469 & 0,185 & 45,215 & 45,016 & 0,199 & 0,014 \\
\hline 6 & 2,1 & 45,986 & 45,807 & 0,179 & 44,760 & 44,562 & 0,198 & 0,019 \\
\hline 7 & 2,5 & 44,485 & 44,312 & 0,173 & 44,260 & 44,058 & 0,202 & 0,029 \\
\hline
\end{tabular}

Os valores obtidos com spark-out nulo foram apresentados na Figura 21. Notase que nas menores velocidades de avanço maior foi a remoção de material. De maneira oposta, quanto maior a velocidade de avanço menor é a quantidade de material removido, confirmado pelo decaimento da curva.

Isso evidencia que, quando o tempo de spark-out é nulo, não existe tempo para recuperação da deformação sofrida pelo sistema RMP introduzidas devido à taxa de remoção de material utilizada e consequentemente que a força normal durante o processo seja suprimida, conforme Figura 20. Quanto maior a deformação introduzida ao processo, para uma mesma rigidez do sistema RMP, maior será a diferença entre o avanço teórico e o avanço real, resultando em um menor sobremetal removido durante o ciclo.

\section{SPARK-OUT ZERO}

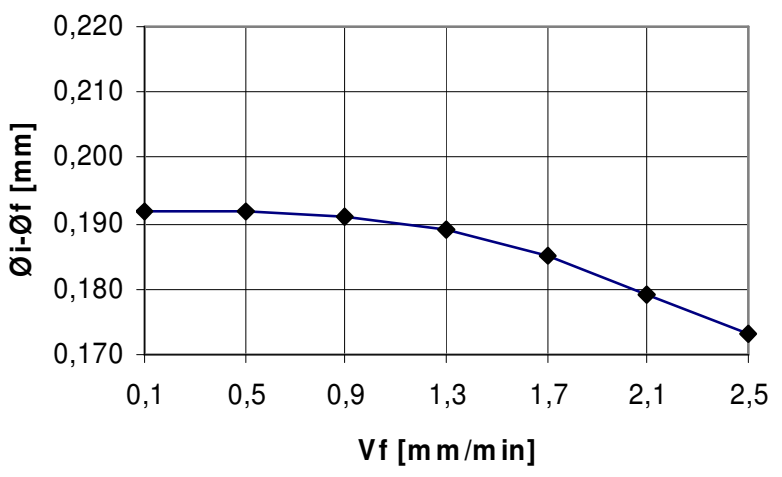

Figura 20. Relação entre a velocidade de avanço e a variação de diâmetro da peça, sem spark-out . 
SPARK-OUT 10

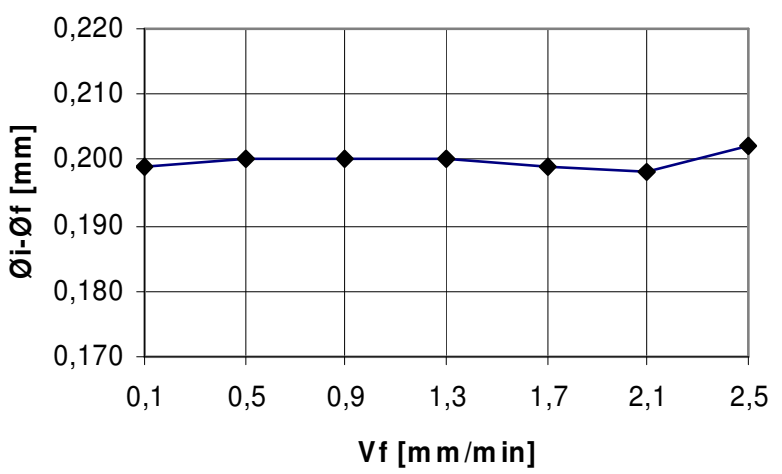

Figura 21. Relação entre a velocidade de avanço e a variação de diâmetro da peça, com spark-out 10 s.

Os valores obtidos com spark-out com duração de $10 \mathrm{~s}$, apresentados na Tabela 4 foram dispostos na Figura 21. Nesse caso busca-se o tempo máximo para supressão das deformações envolvidas. Observa-se, aqui, que um tempo de spark-out longo favoreceu a recuperação elástica do processo, favorecendo que o sistema se recupere das deformações e remova o sobremetal especificado. Nota-se, nesse caso, que praticamente não houve variação no diâmetro final da peça, ou seja, as remoções de material apresentaram-se bastante próximas uma da outra, evidenciado por uma curva aproximadamente reta e horizontal no gráfico da Figura 21. Com isso fica evidenciado que, com spark-out longo o material removido iguala-se àquele programado.

Por fim, foi calculada a deformação ocorrida na máquina para cada uma das velocidades de avanço $\left(\mathrm{V}_{\mathrm{f}}\right)$, o que é representado pela diferença de diâmetro final da peça usinada com spark-out zero $\left(\Delta \emptyset_{\mathrm{o}}\right)$ e o diâmetro final da peça usinada com spark-out de $10 \mathrm{~s}$ $\left(\Delta \emptyset_{10}\right)$, conforme Figura 22.

$$
\Delta \varnothing_{0}-\Delta \varnothing_{10}=\text { Deformação }[\mathrm{mm}]
$$




\section{DEFORM AÇÃO}

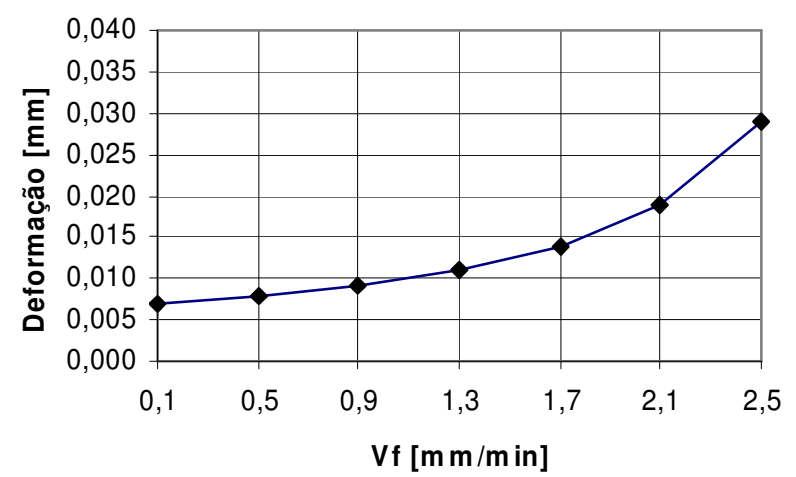

Figura 22. Relação entre a velocidade de avanço e a deformação ocorrida no sistema RMP. Plotagem dos dados apresentados na Tabela 4.

Confirmou-se, assim, que com tempo de spark-out nulo não há tempo suficiente para a máquina retomar suas formas originais, deformadas elasticamente pela força normal de corte. Por outro lado, quando o tempo de spark-out foi de $10 \mathrm{~s}$, houve tempo suficiente para a máquina retomar sua forma original, conferindo uma dimensão mais próxima daquela programada na máquina.

Assim, concluiu-se que a diferença encontrada entre a variação de diâmetro da peça com spark-out zero e spark-out 10 s corresponde à deformação elástica sofrida pela máquina para a velocidade de avanço considerada.

Observando-se as sete peças utilizadas neste ensaio, onde cada uma delas foi usinada com uma velocidade de avanço diferente, nota-se uma relação diretamente proporcional entre a Velocidade de Avanço e a Deformação, como pode ser visualizado na Figura 22. Esperava-se uma relação linear para relação entre a Velocidade de avanço e a Deformação. No entanto isso não ocorreu devido à característica apresentada pelo mancal hidrostático da retificadora Zema que apresenta variação da rigidez para baixas solicitações. 
Fica dessa forma confirmada a relação citada como hipótese deste item, ou seja, quanto maior a velocidade de avanço maior será a deformação introduzida no processo.

\subsection{VALIDAÇÃO DA EXISTÊNCIA DE UMA RELAÇÃO ENTRE A VELOCIDADE DE AVANÇO E A CAPABILIDADE (Cp)}

Na especificação do diâmetro de uma peça define-se tolerância (Tol) como sendo a diferença entre a dimensão máxima (LIE) e a dimensão mínima (LSE) especificadas. A capabilidade do processo $(\mathrm{Cp})$, para obtenção dessa peça, como sendo o quociente entre a tolerância e seis desvios padrão da distribuição; segundo Montgomery (1985) e evidenciado na Figura 23.

$$
\begin{aligned}
& \text { Tol = LSE }- \text { LIE } \\
& \text { Cp= (LSE - LIE }) / 6 \sigma ; \text { onde: }
\end{aligned}
$$

LSE $=$ afastamento superior especificado

LIE $=$ afastamento inferior especificado

LNTI = limite natural de tolerância inferior

LNTS = limite natural de tolerância superior

$\sigma=$ desvio padrão 


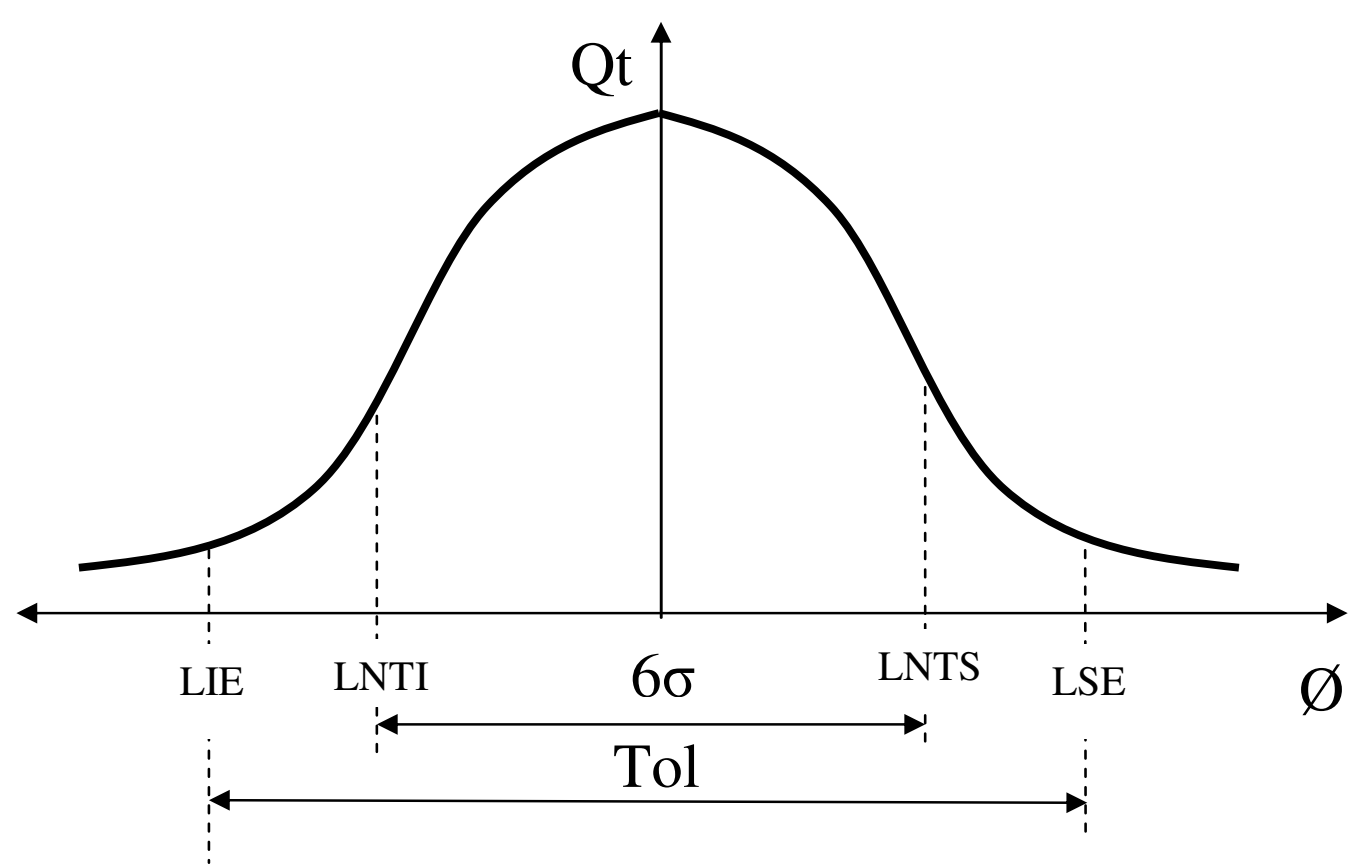

Figura 23. Distribuição normal do diâmetro de uma amostra de peças. (AMARAL; ROZENFELD, 2006)

Dentre as três subfases de usinagem: desbaste, pré-acabamento e acabamento é na terceira e última delas onde a dimensão do diâmetro final é conferida à peça, considerandose um tempo de spark-out pequeno - somente o suficiente para garantir circularidade à peça.

É na fase de acabamento onde a velocidade de avanço $\left(\mathrm{Vf}_{3}\right)$ deve ser o suficiente para que o diâmetro da peça fique dentro da faixa de controle (LNTS - LNTI), para um tempo de spark-out fixo. Se a velocidade de avanço for excessiva, o diâmetro da peça localizar-se-á acima do LNTS (nesse caso não houve tempo suficiente para o sistema RMP recuperar-se da deformação o suficiente para que a peça chegasse à sua dimensão requerida ficou com dimensão maior). Por outro lado, se a velocidade de avanço for baixa, a dimensão da peça ficará abaixo do LNTI, porém acima de LIE (nesse caso o tempo para o sistema RMP recuperar-se da deformação foi mais que o suficiente, fazendo com que a dimensão da peça ultrapassasse o requerido - ficando com dimensão menor). Ainda neste ultimo caso houve uma parcela de tempo inútil desfavorecendo a produtividade. 
Deseja-se que o rebolo avance até a uma posição intermediária, entre os extremos acima citados, onde o diâmetro final da peça se situe dentro da faixa de controle; nem mais, nem menos.

Assim deve-se definir a velocidade de avanço $\left(\mathrm{Vf}_{3}\right)$ para que o diâmetro final da peça apresente uma variação de modo a se situar dentro da faixa de controle, isto é, dentro $\operatorname{dos} 6 \sigma$.

Para tal, adota-se uma velocidade de avanço alta (Vfo); isto é, que esteja situada aproximadamente no topo da escala de valores especificados pelo fabricante do rebolo ou que leve a máquina a consumir uma potencia próxima de $100 \%$ da potencia disponível, por exemplo. A seguir usina-se uma peça com tempo de spark-out nulo, obtendo-se o diâmetro $\mathrm{D}_{0}$ e uma outra com tempo de spark-out 10 s, obtendo-se o diâmetro $\mathrm{D}_{10}$. Salienta-se aqui que a diferença entre os valores desses dois diâmetros $(\Delta \emptyset)$ corresponde à deformação da máquina relativa à velocidade de avanço adotada. Denominamos esta fase como Teste de Rigidez da Máquina.

Conhecendo-se esses dois diâmetros têm-se:

$$
\mathrm{D}_{0}-\mathrm{D}_{10}=\Delta \emptyset=\text { Deformação da Máquina }
$$

A velocidade de avanço $\left(\mathrm{Vf}_{3}\right)$ para que o diâmetro da peça fique dentro dos $6 \sigma$ será obtida como segue, adotando-se essa relação como linearmente proporcional. Vimos que, quando a peça for usinada com uma velocidade de avanço Vfo apresentará uma deformação $\Delta \emptyset$. Assim determina-se a velocidade de avanço para uma deformação igual a $6 \sigma:$

$$
\begin{aligned}
& \text { Vfo-------------------- } \Delta \emptyset \\
& \mathrm{Vf}_{3} \text {----------------6 } \sigma \quad \Rightarrow \mathrm{Vf}_{3}=\mathrm{Vfo}^{*}(6 \sigma / \Delta \emptyset)
\end{aligned}
$$

$\mathrm{Vf}_{3}$ será, então, a velocidade de avanço a ser atribuída à fase final da usinagem 
da peça, isto é, a fase de acabamento.

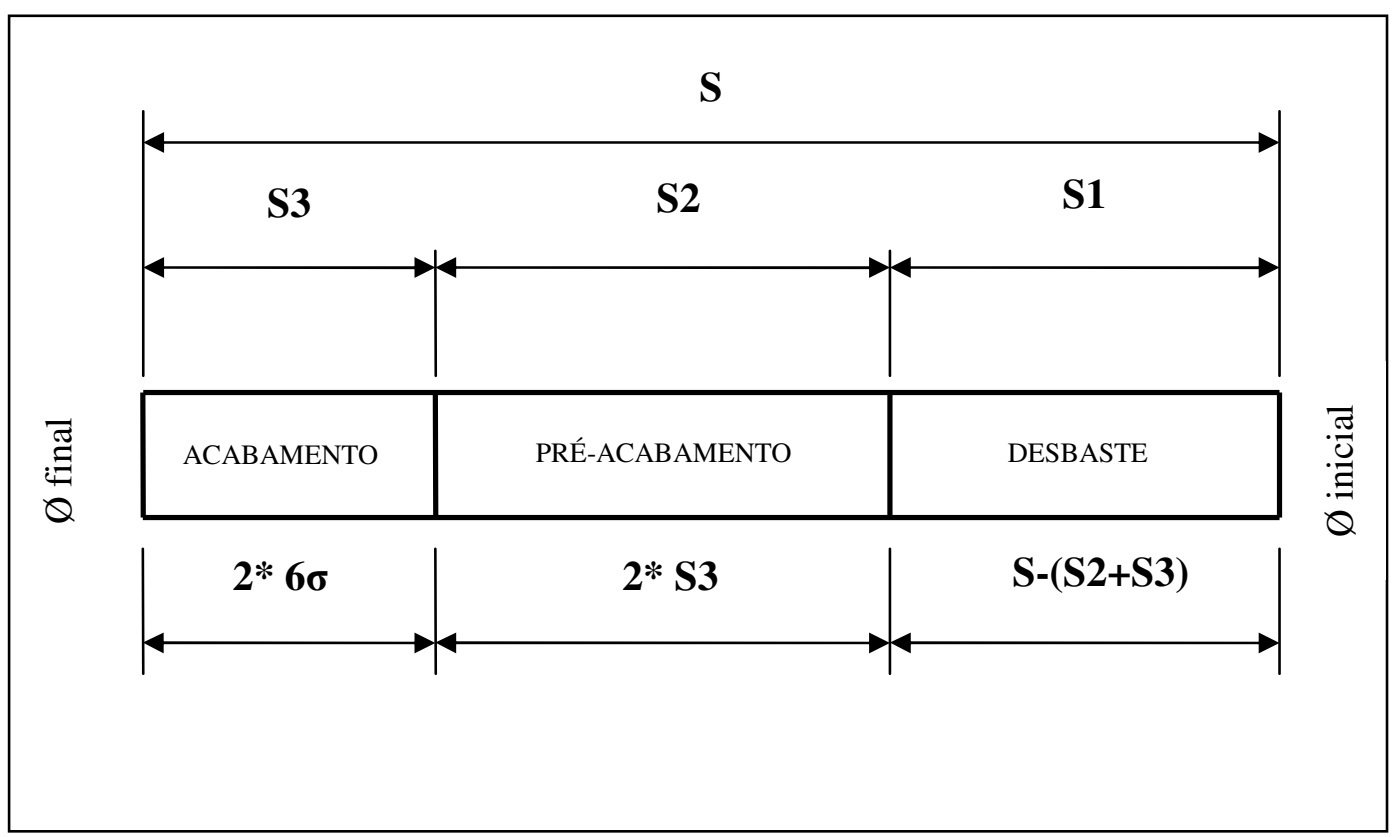

Figura 24. Relação entre os sobremetal em cada subfase.

Faz-se necessário, agora, definir o sobremetal para cada uma das fases da usinagem. Define-se S como sendo o sobremetal especificado, S1 a parcela do sobremetal a ser removido na subfase de desbaste, S2 a parcela a ser removida na subfase de pré acabamento e por fim S3 a parcela deste a ser removida na fase de acabamento. Adota-se o valor para S3 como sendo o dobro do valor $6 \sigma$, por ser a velocidade de avanço anterior $\left(\mathrm{Vf}_{2}\right)$ o dobro da velocidade de avanço atual $\left(\mathrm{Vf}_{3}\right)$. Assim $\mathrm{S} 3=2 * 6 \sigma$. Já podemos também calcular o tempo desta fase: $\mathrm{T} 3=2 * 6 \sigma / \mathrm{Vf}_{3}$; tendo em vista que a Velocidade de Avanço $\left(\mathrm{Vf}_{3}\right)=$ Sobremetal (S3) / Tempo (T3), conforme Figura24.

Assim ficaram definidos os parâmetros para set-up do ciclo, na fase de acabamento:

$$
V f_{3}=V f o * 6 \sigma / \Delta \emptyset
$$

ACABAMENTO

$$
\mathrm{S3}=2 * 6 \sigma
$$

$$
\mathrm{T3}=2 * 6 \sigma / \mathrm{Vf}_{3}
$$


Na subfase pré-acabamento a velocidade de avanço será adotada como sendo o dobro daquela do acabamento: $\mathrm{Vf}_{2}=2 * \mathrm{Vf}_{3}$ e o sobremetal será adotado como sendo o dobro daquele da fase de acabamento: $\mathrm{S} 2=2 * \mathrm{~S} 3$; portanto o tempo nesta subfase será................... $\mathrm{T} 2=\mathrm{S} 2 / \mathrm{Vf}_{2}$

Assim ficaram definidos os parâmetros para set-up do ciclo, na fase de préacabamento:

$$
\mathrm{Vf2}=2 * \mathrm{Vf}_{3}
$$

PRÉ-ACABAMENTO S2 $=2 * \mathrm{S3}$

$$
\mathrm{T} 2=\mathrm{S} 2 / \mathrm{Vf}_{2}
$$

Na subfase desbaste a velocidade de avanço será adotada como sendo o dobro daquela da subfase de pré-acabamento: $\mathrm{Vf}_{1}=2 * \mathrm{Vf}_{2}$ e o sobremetal será o restante a ser removido, ou seja, será a diferença entre aquele especificado para a matéria prima $(\mathrm{S})$ e a somatória daqueles já removidos nas subfases anteriores: $\quad \mathrm{S} 1=\mathrm{S}-(\mathrm{S} 2+\mathrm{S} 3)$; portanto o tempo dessa subfase será $\mathrm{T} 1=\mathrm{S} 2 / \mathrm{Vf}_{1}$.

Assim ficaram definidos os parâmetros para set-up do ciclo, na fase de desbaste:

$$
V f_{1}=2 * V f_{2}
$$

DESBASTE

$$
\mathbf{S 1}=\mathbf{S}-(\mathbf{S 2}+\mathbf{S 3})
$$

$$
\mathbf{T} 1=\mathbf{S} 2 / \mathbf{V f}_{\mathbf{1}}
$$


Na fase de spark-out, como já citado, o tempo será ajustado de forma a conferir rugosidade e circularidade conforme especificação da peça. Para inicio do set-up adotaremos o tempo de spark-out T4 = 0,5 s (anotado nas Figuras 25 a 27 como SPKT).

Os tempos de aproximação, de troca de peça e de recuo deverão ser acrescidos ao tempo de usinagem para obtenção do tempo do ciclo total.

O tempo total do ciclo de usinagem (T) será, então, a somatória dos tempos parciais:

$$
\mathrm{T}=\mathrm{T} 1+\mathrm{T} 2+\mathrm{T} 3+\mathrm{T} 4
$$

Para esta atividade foram disponibilizadas doze peças. Cada uma delas foi fixada na placa da máquina e foi anotada a posição em que coincide com uma determinada castanha. Em sequencia foi dado um passe de $0,020 \mathrm{~mm}$, dessa forma regularizaram-se as superfícies das peças.

Cada uma das peças, antes da usinagem, foi novamente fixada na placa fazendo-se coincidir com a mesma posição relação à placa definida no processo de regularização citado.

Fixada uma peça foi feito a aproximação do rebolo manualmente até que se observasse visualmente o inicio de centelhas. A partir deste ponto o rebolo foi afastado da peça a uma distancia de $100 \mathrm{~mm}$, estabelecendo-se esta como a posição referencial do rebolo antes de iniciar as usinagens.

As duas primeiras peças, dentre as doze, foram utilizadas para realização do Teste de Rigidez da máquina. Para isso ajustou-se a máquina com a maior velocidade de avanço tolerada, nesse e caso o fator limitante foi a capacidade de usinagem do rebolo. A velocidade de avanço máxima recomendado pelo fabricante para o rebolo 38-A-80-KVHB é 
de 0,005 mm por rotação da peça, para aços de baixo teor de carbono (NORTON, 2001). Sendo esta rotação 300 rpm, temos a velocidade de avanço adotada:

$$
\mathrm{Vfo}=0,005.300 \quad=>\quad \mathrm{Vfo}=1,2 \mathrm{~mm} / \mathrm{s}
$$

O sobremetal adotado foi de $0,300 \mathrm{~mm}$.

Após a usinagem foram obtidos os resultados indicados na Tabela 5. A máquina apresentou uma deformação $(\Delta \emptyset)$ de $0,014 \mathrm{~mm}$ para a velocidade de avanço $\mathrm{Vfo}=1,2 \mathrm{~mm} / \mathrm{s}$.

Note que o valor $\mathrm{D}_{0}$, aqui, está sendo representado pelo valor $\Delta_{0}$ e $\mathrm{D}_{10}$ pelo valor $\Delta 10$, pois o diâmetro inicial das peças não é exatamente o mesmo, se o fossem $\Delta_{0}$ seria igual a $\mathrm{D}_{0}$ e $\mathrm{D}_{10}$ igual a $\Delta_{10}$, o que não influi no resultado final.

Tabela 5 - Parâmetros para realização do Teste de Rigidez. Unidades: mm/min; mm; s.

\begin{tabular}{rcc}
\hline $\mathrm{Vfo}=1,200$ & $\mathrm{~S}=0,300$ \\
\hline \multicolumn{3}{c}{} \\
\hline spark-out 0 & spark-out 10 & $\Delta \emptyset=\Delta_{0}-\Delta_{10}$ \\
\hline \multicolumn{3}{c}{} \\
\hline$\varnothing \mathrm{f}=47,891$ & $\varnothing \mathrm{i}=47,887$ \\
\hline$\Delta_{0}=0,286$ & $\varnothing \mathrm{f}=47,587$ \\
\hline
\end{tabular}

Para o ensaio foram adotados três índices de capabilidade $(\mathrm{Cp}): 1,25 ; 1,33$ e 2,25 .

Considerando conhecida a tolerância, sendo ela de 0,017 mm (é um dado de entrada do processo, obtido do desenho do produto, por exemplo), e adotando-se um tempo de 
spark-out de 0,5 s foram calculadas, para cada valor da capabilidade $(\mathrm{Cp})$, as velocidades de avanço nas três subfases (desbaste, pré-acabamento e acabamento) pelo método já descrito. Esses métodos estão resumidos nas Figuras 25, 26 e 27. As fórmulas para obtenção de cada um dos valores estão representadas logo abaixo de cada um deles:

Observa-se que as velocidades de avanço nas fases pré-acabamento e desbaste obtidas no método proposto são maiores que a velocidade máxima de avanço recomenda, em função da especificação do rebolo - $1,2 \mathrm{~mm} / \mathrm{min}$, como concluído na página 62 . Nesse caso a máquina foi ajustada para a velocidade de avanço máxima recomenda e não aquelas $\left(\mathrm{Vf}_{1}\right.$ e $\mathrm{Vf}_{2}$ ) indicadas nas Figuras 25, 26 e 27.

ESPECIFICAÇÃO
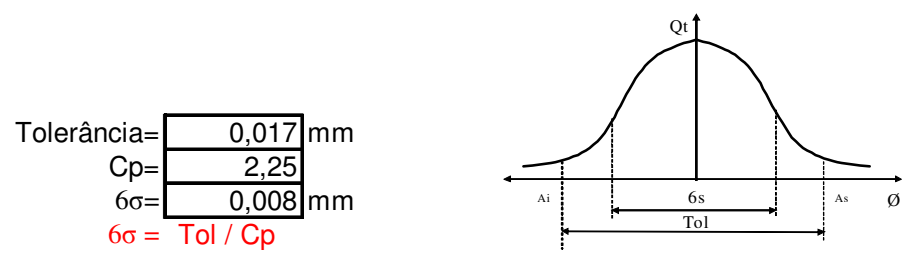

\begin{tabular}{|c|c|c|c|c|c|}
\hline & $\mathrm{mm} / \mathrm{min}$ & & $\mathrm{mm}$ & & $\mathrm{s}$ \\
\hline \multirow[t]{2}{*}{ DESBASTE } & $V f 1=2,59$ & $S 1=$ & \begin{tabular}{|l|}
0,255 \\
\end{tabular} & $\mathrm{~T} 1=[$ & 5,90 \\
\hline & $=2^{*} \mathrm{Vf} 2$ & & $=\mathrm{S}-(\mathrm{S} 2+\mathrm{S} 3)$ & & $=\mathrm{S} 1 / \mathrm{Vf1}$ \\
\hline \multirow[t]{2}{*}{ PRÉ-ACABAMENTO } & $V f 2=1,30$ & $\mathrm{~S} 2=$ & \begin{tabular}{|l|}
0,030 \\
\end{tabular} & $\mathrm{~T} 2=$ & 1,39 \\
\hline & $=2^{*} \mathrm{Vf3}$ & & $=2 * \mathrm{~S} 3$ & & $=\mathrm{S} 2 / \mathrm{V} f 2$ \\
\hline \multirow[t]{2}{*}{ ACABAMENTO } & $V f 3=0,65$ & S3 $=$ & \begin{tabular}{|l|}
0,015 \\
\end{tabular} & $T 3=[$ & 1,38 \\
\hline & $=\mathrm{Vfo}{ }^{*}(6 \sigma / \Delta \varnothing)$ & & $=2^{*} 6 \sigma$ & & $=\mathrm{S} 3 / \mathrm{Vf} 3$ \\
\hline \multirow[t]{6}{*}{ SPARK-OUT } & & & & $\mathrm{SPKT}=[$ & 0,5 \\
\hline & & \multicolumn{3}{|c|}{ Ciclo de usinagem $=$} & 9 \\
\hline & & \multirow{3}{*}{\multicolumn{3}{|c|}{$\begin{array}{r}\text { Alimentação }= \\
\text { Aproximação }= \\
\text { Recuo }=\end{array}$}} & 10 \\
\hline & & & & & 2 \\
\hline & & & & & 1 \\
\hline & & \multicolumn{3}{|c|}{ Ciclo total $=$} & 22 \\
\hline
\end{tabular}

Figura 25. Método para calculo das velocidades de avanço com $\mathrm{Cp}=1,25$ 
ESPECIFICAÇÃO
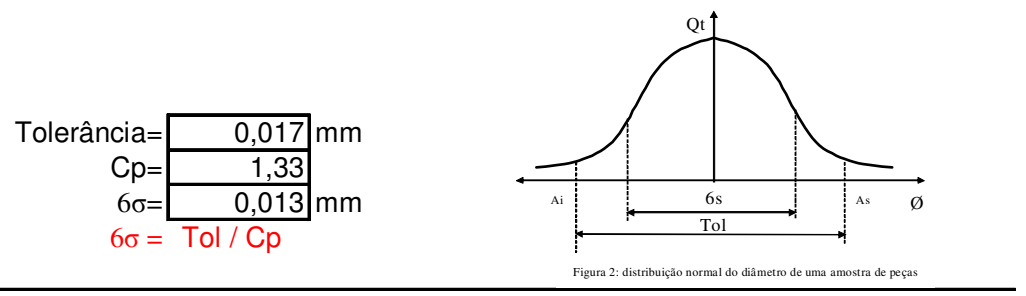

\begin{tabular}{|c|c|c|c|c|c|c|}
\hline & & $\mathrm{mm} / \mathrm{min}$ & & $\mathrm{mm}$ & & $s$ \\
\hline \multirow[t]{2}{*}{ DESBASTE } & $V f 1=$ & 4,38 & $\mathrm{~S} 1=$ & 0,223 & $\mathrm{~T} 1=$ & 3,06 \\
\hline & & $=2^{*} \mathrm{Vf2}$ & & $=\mathrm{S}-(\mathrm{S} 2+\mathrm{S} 3)$ & & $=\mathrm{S} 1 / \mathrm{Vf1}$ \\
\hline \multirow{2}{*}{ PRÉ-ACABAMENTO } & $\mathrm{Vf2}=[$ & 2,19 & $\mathrm{~S} 2=$ & 0,051 & $\mathrm{~T} 2=$ & 1,39 \\
\hline & & $=2^{*} \mathrm{Vf3}$ & & $=2^{*} \mathrm{~S} 3$ & & $=\mathrm{S} 2 / \mathrm{Vf} 2$ \\
\hline \multirow[t]{2}{*}{ ACABAMENTO } & $\mathrm{Vf} 3=[$ & \begin{tabular}{|l|}
1,10 \\
\end{tabular} & $\mathrm{~S} 3=$ & \begin{tabular}{|l|}
0,026 \\
\end{tabular} & $\mathrm{~T} 3=$ & 1,38 \\
\hline & & $=V f o^{*}(6 \sigma / \Delta \varnothing)$ & & $=2^{*} 6 \sigma$ & & $=\mathrm{S} 3 / \mathrm{Vf3}$ \\
\hline \multirow[t]{6}{*}{ SPARK-OUT } & & & & & $\mathrm{SPKT}=$ & 0,5 \\
\hline & & & \multicolumn{3}{|c|}{ Ciclo de usinagem $=$} & 6 \\
\hline & & & & \multirow{3}{*}{\multicolumn{2}{|c|}{$\begin{array}{r}\text { Alimentação }= \\
\text { Aproximação }= \\
\text { Recuo }=\end{array}$}} & 10 \\
\hline & & & & & & 2 \\
\hline & & & & & & 1 \\
\hline & & & & \multicolumn{2}{|c|}{ Ciclo total $=[$} & 19 \\
\hline
\end{tabular}

Figura 26. Método para calculo das velocidades de avanço com $\mathrm{Cp}=1,33$.

ESPECIFICAÇÃO
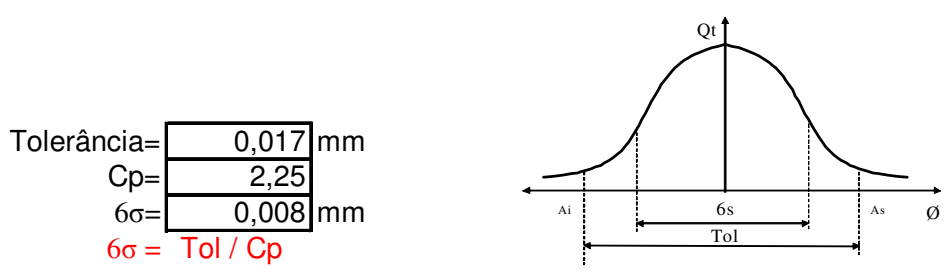

$\begin{array}{lc} & \mathrm{mm} / \mathrm{min} \\ \text { DESBASTE } & \mathrm{Vf} 1=\frac{2,59}{=} \\ \text { PRÉ-ACABAMENTO } & \mathrm{V} \mathrm{V} 2=\frac{1,30}{} \\ & =2^{*} \mathrm{Vf} 3 \\ \text { ACABAMENTO } & \mathrm{Vf} 3=\frac{0,65}{}=\mathrm{Vfo}(6 \sigma / \Delta \varnothing)\end{array}$

$\begin{aligned} & \mathrm{mm} \\ \mathrm{S} 1= & 0,255 \\ = & \mathrm{S}-(\mathrm{S} 2+\mathrm{S} 3) \\ \mathrm{S} 2= & 0,030 \\ = & =2^{*} \mathrm{~S} 3 \\ \mathrm{~S} 3= & 0,015 \\ = & =2^{*} 6 \sigma\end{aligned}$

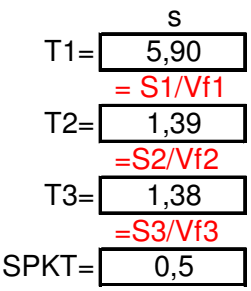

Ciclo de usinagem

9

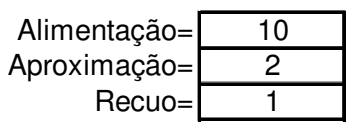

Ciclo total $=\square 22$

Figura 27. Método para calculo das velocidades de avanço com $\mathrm{Cp}=1,20$. 


\section{RESULTADOS - ANÁLISE E DISCUSSÃO}

Para cada valor da capabilidade adotada $(\mathrm{Cp})$ foram usinadas 6 peças, os valores dos diâmetros finais obtidos estão anotados na Tabela 6. Desses valores foram calculados também a média, a amplitude e a capabilidade $(\mathrm{Cp})$ efetiva.

Os valores anotados na Tabela 6 são apresentados nas Figuras 28, 29 e 30.

Tabela 6 - Resultados após usinagem das três amostras.

\begin{tabular}{|c|c|c|c|}
\hline Vf3 & 0,65 & 1,10 & 1,17 \\
\hline Cp previsto & $\mathbf{2 , 2 5}$ & $\mathbf{1 , 3 3}$ & $\mathbf{1 , 2 5}$ \\
\hline \multicolumn{4}{|c|}{} \\
\hline peça 1 & $\mathbf{4 6 , 1 8 6}$ & $\mathbf{4 5 , 8 9 7}$ & $\mathbf{4 5 , 5 5 5}$ \\
\hline peça 2 & $\mathbf{4 6 , 1 8 9}$ & $\mathbf{4 5 , 9 0 2}$ & $\mathbf{4 5 , 5 5 3}$ \\
\hline peça 3 & $\mathbf{4 6 , 1 8 9}$ & $\mathbf{4 5 , 8 9 6}$ & $\mathbf{4 5 , 5 5 7}$ \\
\hline peça 4 & $\mathbf{4 6 , 1 8 9}$ & $\mathbf{4 5 , 9 0 0}$ & $\mathbf{4 5 , 5 6 0}$ \\
\hline peça 5 & $\mathbf{4 6 , 1 8 9}$ & $\mathbf{4 5 , 9 0 0}$ & $\mathbf{4 5 , 5 5 8}$ \\
\hline peça 6 & $\mathbf{4 6 , 1 9 0}$ & $\mathbf{4 5 , 9 0 1}$ & $\mathbf{4 5 , 5 5 8}$ \\
\hline \multicolumn{4}{|c|}{} \\
\hline media & 46,189 & 45,899 & 45,557 \\
\hline tol & 0,017 & 0,017 & 0,017 \\
\hline$\sigma$ & 0,0014 & 0,0023 & 0,0025 \\
\hline $6 \sigma$ & 0,008 & 0,014 & 0,015 \\
\hline Cp $p_{\text {real }}$ & $\mathbf{2 , 0 7}$ & $\mathbf{1 , 2 1}$ & $\mathbf{1 , 1 4}$ \\
\hline
\end{tabular}

\section{$V f=0,65 \mathrm{~m} \mathrm{~m} / \mathrm{min} \quad C p=2,25$}

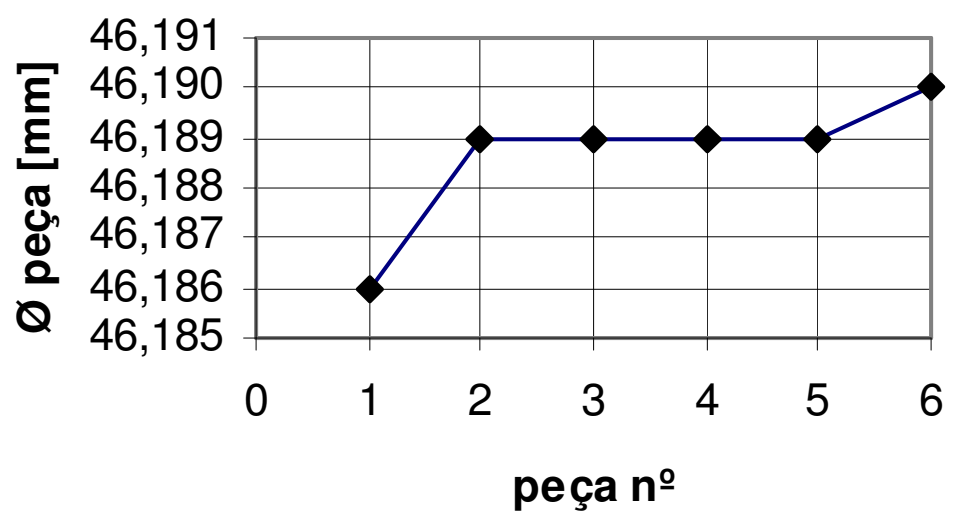

Figura 28. Diâmetro obtido para cada uma das peças usinadas com $\mathrm{Vf}_{3}=0,65 \mathrm{~mm} / \mathrm{min}$ e $\mathrm{Cp}=2,25$. 


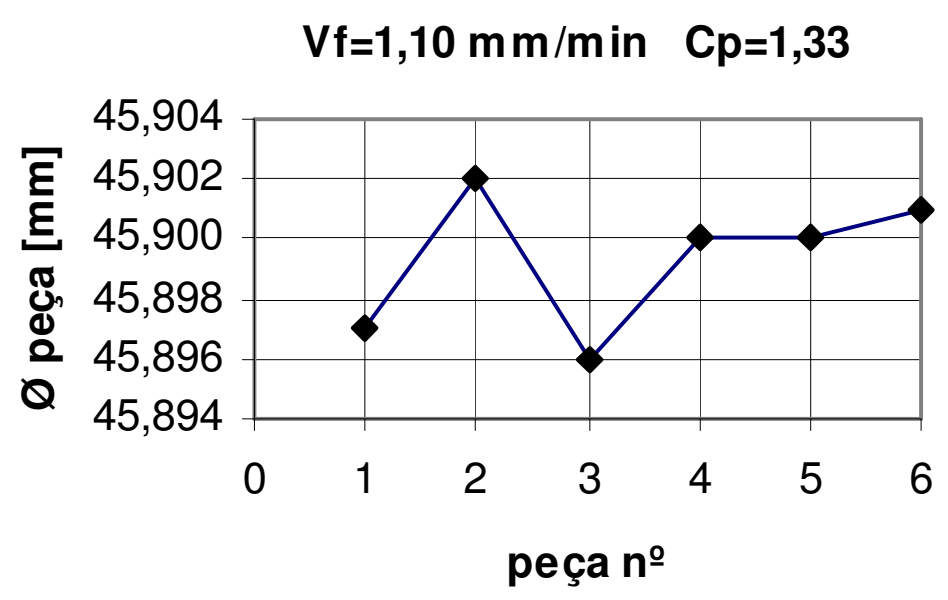

Figura 29. Diâmetro obtido para cada uma das peças usinadas com $\mathrm{Vf}_{3}=1,10 \mathrm{~mm} / \mathrm{min}$ e $\mathrm{Cp}=1,33$.

\section{$V f=1,17 \mathrm{~mm} / \mathrm{m}$ in $C p=1,25$}

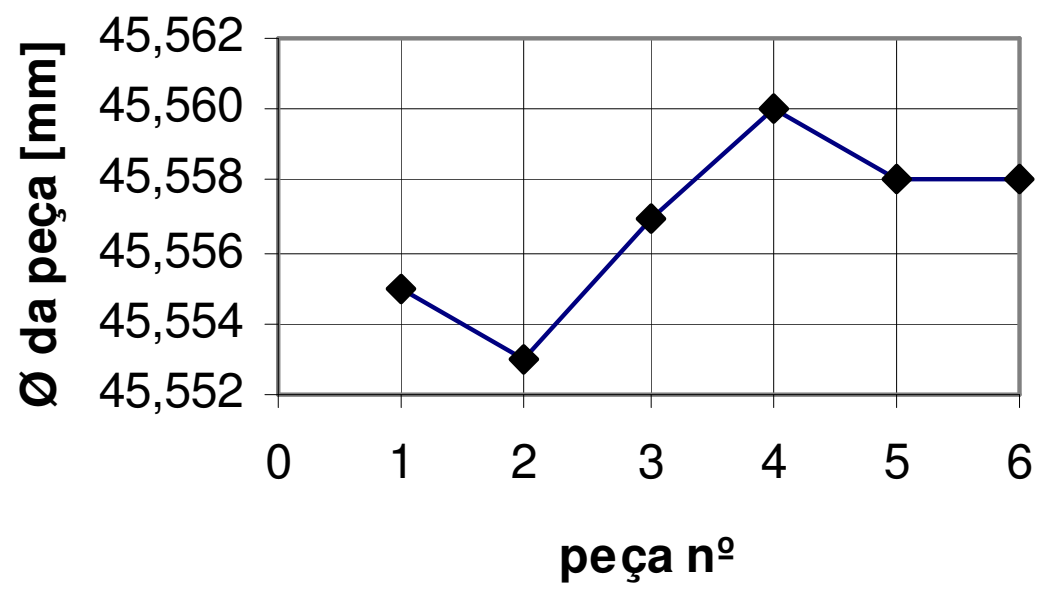

Figura 30. Diâmetro obtido para cada uma das peças usinadas com $\mathrm{Vf}_{3}=1,17 \mathrm{~mm} / \mathrm{min}$ e $\mathrm{Cp}=1,25$.

Observando-se a Tabela 6 nota-se uma relação direta entre velocidade de avanço e a dispersão das dimensões da amostra, evidenciado pelos valores obtidos para os desvios padrão $(\sigma)$, conforme Tabela 7 : 
Tabela 7 - Variação do desvio padrão em função da velocidade de avanço

\begin{tabular}{cccc}
\hline $\mathrm{Vf}$ & 0,65 & 1,10 & 1,17 \\
$(\mathrm{~mm} / \mathrm{min})$ & & & \\
\hline$\sigma(\mathrm{mm})$ & 0,0014 & 0,0023 & 0,0025 \\
\hline
\end{tabular}

A relação entre as capabilidades previstas e as capabilidades reais guardou uma relação direta e os valores reais ficaram próximos dos valores esperados, como extraído da Tabela 8 e evidenciado na Figura 31.

Tabela 8 - Comparativo entre a capabilidade prevista e a capabilidade efetiva obtida

\begin{tabular}{llll}
\hline Cp prevista & 2,25 & 1,33 & 1,17 \\
\hline Cp efetiva & 2,07 & 1,21 & 1,14 \\
\hline
\end{tabular}

Isto nos leva a concluir que o modelo de cálculo e estimativa da capabilidade do processo proposto pode nos levar a um resultado prático próximo daquele esperado, por ocasião da tarefa de se obter uma otimização nos tempos de usinagem.

Foram extraídos da Tabela 6 os valores da Velocidade de Avanço e da Capabilidade os quais estão apresentados na Figura 32. Nota-se que estes parâmetros guardam uma proporção inversa entre si. 
Cp previsto x Cp real

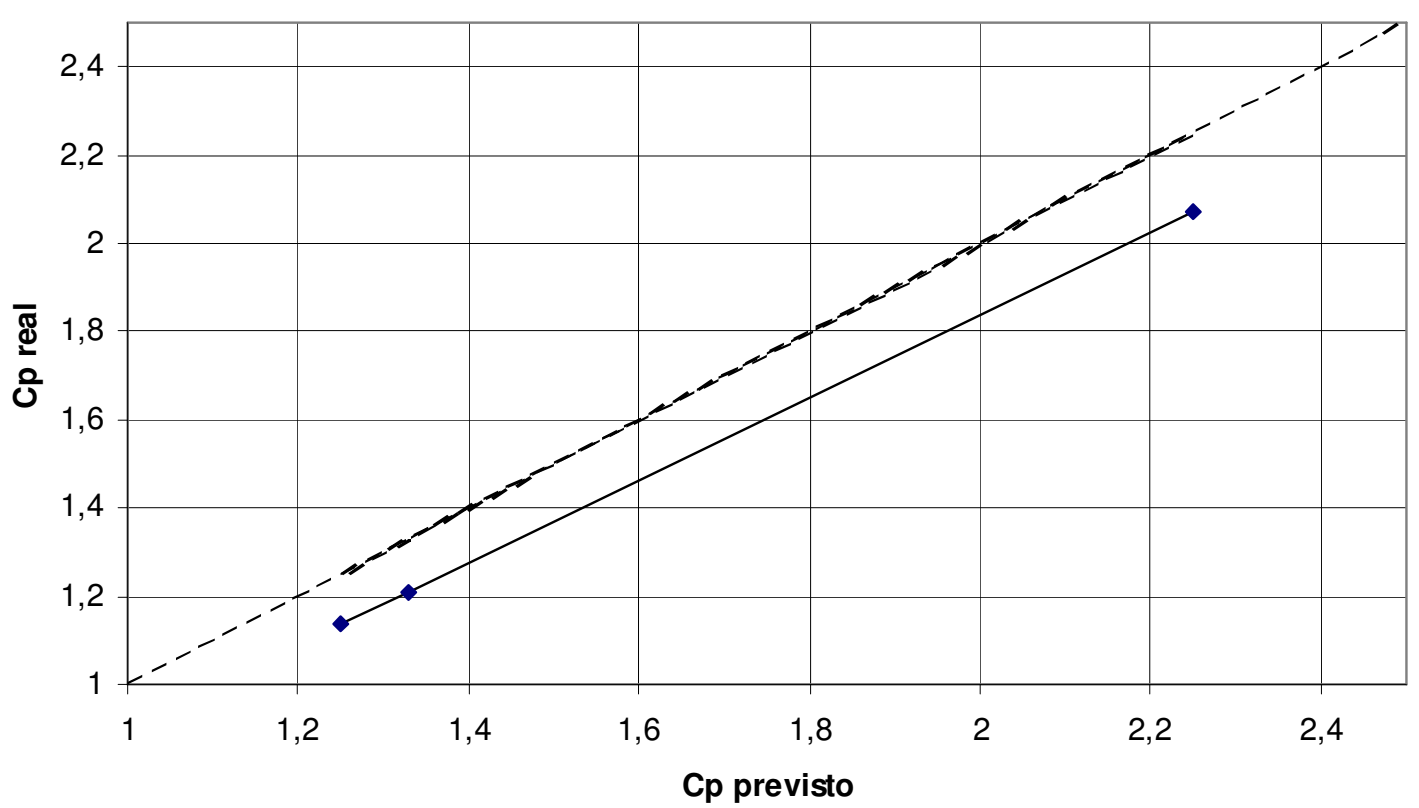

Figura 31. Relação entre a Cp previsto e Cp real

\section{Vf $x$ Cp real}

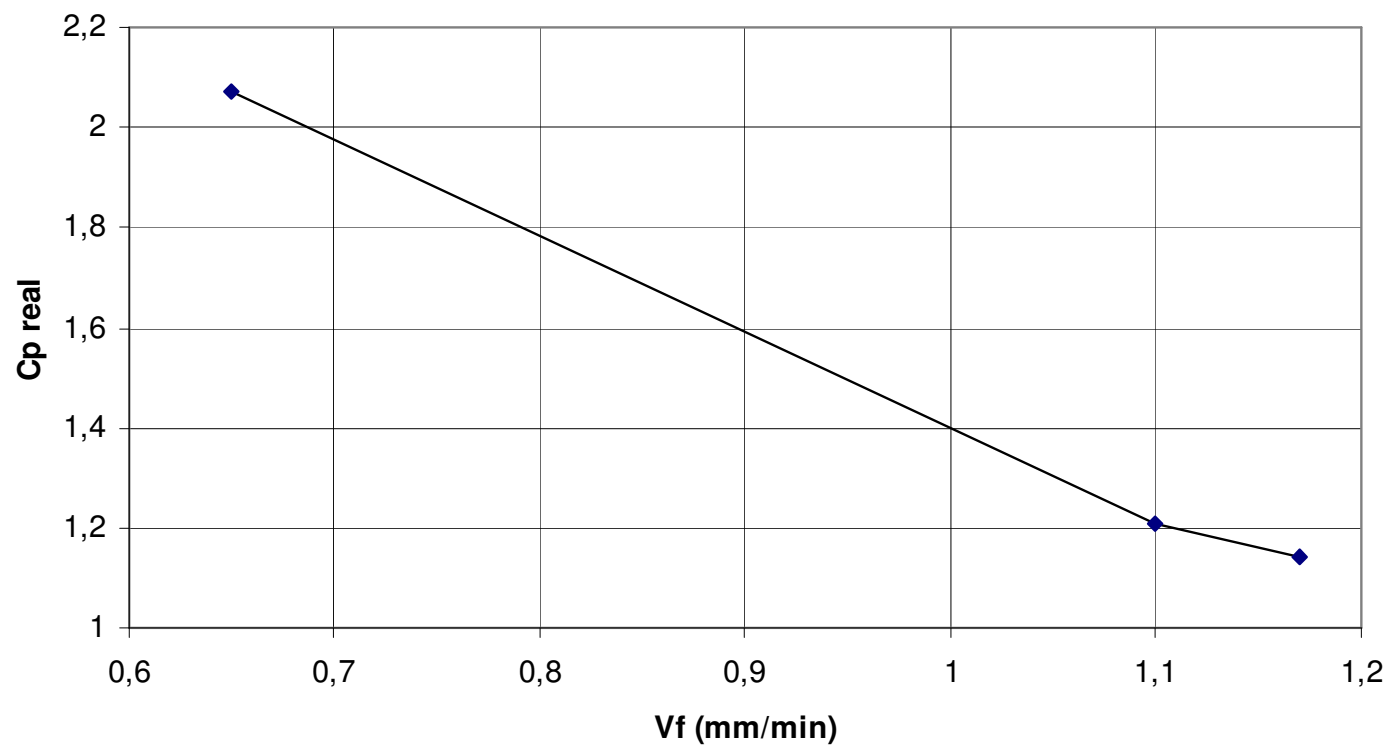

Figura 32. Relação proporcional entre a velocidade de avanço do rebolo (Vf) e a capabilidade real do processo (Cp real) 
Ressaltando o já citado no final do item 4.5, quando a velocidade de avanço; determinada por esse método, superou a velocidade de avanço máxima recomendada; a máquina foi ajustada para a velocidade de avanço máxima admitida pelo rebolo. Com a redução desta velocidade de avanço o tempo de ciclo aumentou, porém o resultado não influenciou na obtenção da capabilidade do processo, pois a velocidade de avanço na subfase de acabamento foi menor que a velocidade recomendada e, portanto foi mantida.

Para se utilizar as velocidades obtidas pelo método aqui apresentado seria necessário utilizar um rebolo que suportasse uma maior taxa especifica de remoção de material. Para isso deve-se utilizar um rebolo que apresente condições para trabalhar com maior velocidade de avanço (observando-se sempre se não está ocorrendo queima da peça) com isso teríamos uma redução no tempo do ciclo. 


\section{CONCLUSÕES}

Comprovou-se que a deformação da máquina é proporcional à velocidade de avanço. A linearidade desta relação foi obtida em virtude do comportamento do mancal hidrostático da retificadora utilizada - variação da rigidez à baixas solicitações.

O método proposto para otimização do ciclo de usinagem em processo produtivo se mostrou eficaz, já que para a situação de retificação de produção testada pôde-se garantir a capabilidade do processo retificado.

A capabilidade do processo é conclusivamente proporcional à velocidade de avanço utilizada na usinagem, confirmando a hipótese desta pesquisa. 


\section{SUGESTÕES PARA TRABALHOS FUTUROS}

É recomendável a continuidade de pesquisas com este tema, pois muitas lacunas ainda estão abertas e disponíveis para estudos futuros.

A utilização de um tipo de rebolo que atenda a uma maior taxa especifica de remoção de material é uma questão que pode reduzir muito o tempo de ciclo aqui proposto. Isto está disponível para estudos e para novas propostas.

Seria muito interessante estender este método para outras formas de usinagem por abrasão além desta aqui referida - a retificação por mergulho, como a retificação cilíndrica tangencial, a retificação tangencial plana e a retificação centerless de passagem. 


\section{REFERÊNCIAS BIBLIOGRÁFICAS *}

AMARAL D. C., ROZENFELD H. (2006), Engenharia de Produção. Índices de Capabilidade do Processo. Disponível em http://engenharia.alol.com.br/joomla/content/view/204/64/. Acesso em 06 jul.2007.

BENKO, G. (1999) Economia, espaço e globalização: na aurora do século XXI, tradução: Antonio de Pádua Danesi, $2^{a}$ ed. Hucitec, São Paulo.

CINCINNATI MILACRON (1996) Grinding principles and practice, Seminar, Ohio, USA

DATALYZER Disponível em

<http://www.datalyzer.com.br/site/suporte/administrador/info/arquivos/info57/57.html.> Acesso em 20 jul.2007.

DUBBEL handbook of mechanical engineering. (1994) Springer-Verlag. New York.

GALEGO, et al. (2006) Precision, stability and productivity increase in throughfeed centerless grinding, Annals of the CIRP, v.55, n.1.

GIMENEZ J. G.; NIETO, F. J. (1994) A step by step approach to the dinamic behavior of centerless grinding machines. Tools Manufacture, Great Britain, v.35, n9, p.1291-1307, 1995.

HAMMER, M. (2000) A Agenda: o que as empresas devem fazer para dominar esta década, tradução: Afonso Celso da Cunha Serra, ed. Campus, 2001, Rio de Janeiro

ILO International Labour Organization (2007). Disponível em

$<$ http://www.ilo.org/public/english/employment/strat/kilm/index.htm>. Acesso em:

10nov.2007.

GIMENEZ J. G.; NIETO, F. J. (1994) A step by step approach to the dynamic behavior of centerless grinding machines. Tools Manufacture, Great Britain, v.35, n.9, p.1291-1307, 1995.

KONIG, W. (1980) Retificação, brunimento e lapidação. Tradução de Walter Lindolfo Weingaertner.

LIZARRALDE R. et al, (2005) Practical application of new simulation methods for the elimination of geometric instability in centerless grinding, Annals of the CIRP.

MALKIN, S (1981) Grinding cycle optimization, Annals of the CIRP, v.30, n.1, p.223-226

MEDALHA, G.C. (2001) Nova metodologia para monitoramento dimensional de peças, em processo, utilizando uma retificadora cilíndrica. 115 p. Dissertação (Mestrado) Escola de Engenharia de São Carlos, Universidade de São Paulo, São Carlos, 2001.

MONTGOMERY, D. C. (1985) Introduction to statistical quality control, ed. John Wiley \& Sons, EUA. 
NAKAYAMA. K. et alli (1980) Sharpness evaluation of grinding wheel face by the grinding of steel ball. In: Annals of the CIRP, 29/1, 1980. p.227-228

NORTON (2001). Guidelines for improved cylindrical grinding. Saint Gobain Abrasives, Inc, Form \#7154 A

OLIVEIRA, J. F. G. (1988) Análise da ação do macroefeito de dressagem de rebolos no desempenho do processo de retificação. 272 p. Tese (Doutorado) - Escola de Engenharia de São Carlos, Universidade de São Paulo, São Carlos, 1988.

PEREIRA, W. X.; Hassui, A.; Diniz A. E. (2004). Otimização do processo de retificação de mergulho na presença de medidor radial. Máquinas e Materiais, São Paulo, v.40, n.1, p.126-134

SIMNOFSKE M.; HESSELBACH, J. (2006) The increase of dynamic and static stiffness of a grinding machine, In: 2006 ASME INTERNATIONAL DESIGN ENGINEERING TECHNICAL CONFERENCES, 2006, Philadelphia.

SLOCUM, H.A. (1992) Precision Machine Design. New Jersey, Prentice Hall

TLUSTY, J. (1970) Static and dynamic stiffness. In: TLUSTY, J. \& KOENIGSBERGER, F. Machine tool structures. Oxford, Pergamon Press, vol.1, cap.1. 519 p. p.72-87.

*De acordo com:

ASSOCIAÇÃO BRASILEIRA DE NORMAS TÉCNICAS. NBR 6023: informação e documentação: referências: elaboração. Rio de Janeiro, 2002. 
APÊNDICE A

MÉTODO PARA DETERMINAÇÃO AUTOMÁTICA DO TEMPO DE SET-UP 
Sugere-se aqui programar o $\mathrm{CNC}$ da retificadora com a lógica de cálculo apresentada nesta pesquisa, configurando-se a tela conforme mostrado nas Figuras 33 a 35.

$\mathrm{Na}$ tela do menu raiz, Figura 33, insere-se um ícone intitulado "Teste de Rigidez" que, quando acionado nos remeterá à tela das condições de contorno (Figura 34). Nessa tela deverão ser informados os parâmetros obtidos no teste de rigidez. Após acionada a entrada desses dados no sistema, os parâmetros de usinagem são carregados automaticamente, sendo, então, apresentada a tela da Figura 35, onde se pode visualizar a programação da máquina. Estes parâmetros de configuração deve nos levar à obtenção do resultado muito próximo do ideal.

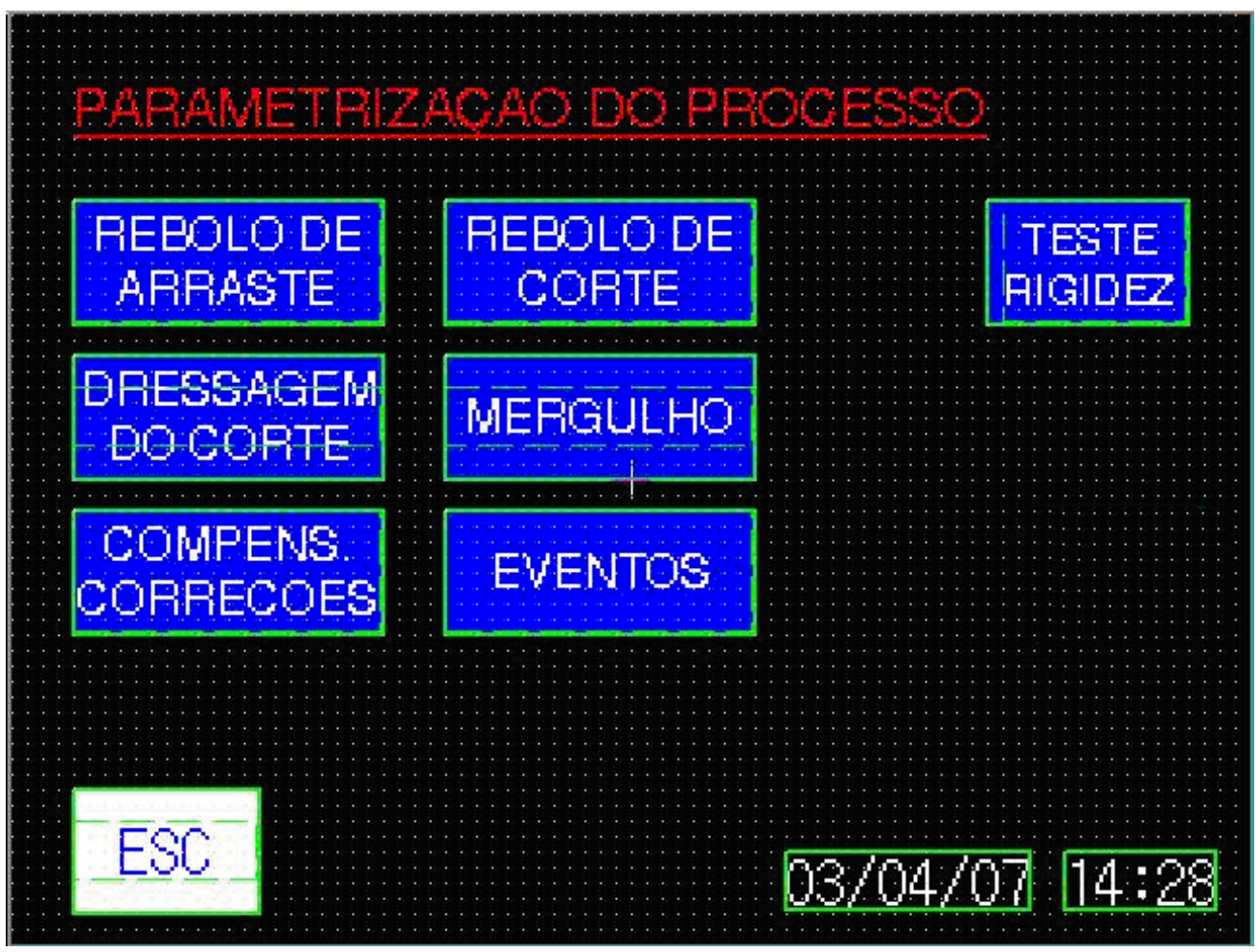

Figura 33. Painel do CNC - Menu raiz 


\section{TESTE OE AIGIOEZ}

Avang

$1.20 \mathrm{~mm} / \mathrm{s}$

Toleranota

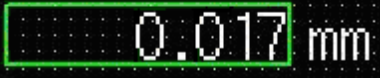

Sobre-meta

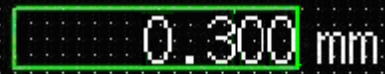
Cpk

\section{Spark-nut}

Ф $\quad 47.68 \mathrm{~mm}$ Фf $47.448 \mathrm{~mm}$

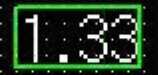

$+\quad 1.38$

\section{Spark-aut 10}

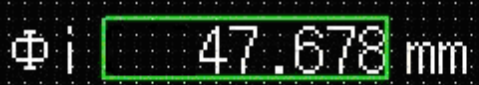

Фf 47.478 mm

\section{ESC}

Figura 34. Painel do CNC - Tela para inserção das condições de contorno.

MEBGUHODAMESA PRIMCAL

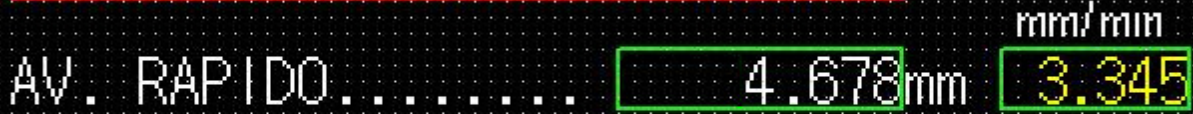

DESBATE ...... 0.278n 2.648

SEM -AOABAMENTO - . 0.078 1.345

ACABAMENTO,_,., 0.018n 0.448

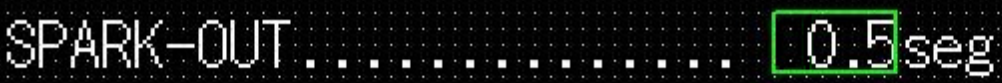

ESC

RET BAPIDO, 6.778m 4.445

Figura 35. Painel do CNC - Tela mostrando a máquina configurada. 